\title{
Contribution of DNMT1 to Neuropathic Pain Genesis Partially through Epigenetically Repressing Kcna2 in Primary Afferent Neurons
}

\author{
${ }^{\circ}$ Linlin Sun, ${ }^{1 *}$ Xiyao Gu, ${ }^{1 *}$ Zhiqiang Pan, ${ }^{1}$ Xinying Guo, ${ }^{1}$ Jianbin Liu, ${ }^{1}$ Fidelis E. Atianjoh, ${ }^{1}$ Shaogen Wu, ${ }^{1}$ Kai Mo, ${ }^{1}$ \\ Bo Xu, ${ }^{1}$ Lingli Liang, ${ }^{1}$ Alex Bekker, ${ }^{1}$ and $\odot Y u a n-X i a n g ~ T a o^{1,2}$ \\ ${ }^{1}$ Department of Anesthesiology, and ${ }^{2}$ Departments of Cell Biology \& Molecular Medicine and Physiology, Pharmacology \& Neuroscience, New Jersey \\ Medical School, Rutgers, State University of New Jersey, Newark, New Jersey 07103
}

\begin{abstract}
Expressional changes of pain-associated genes in primary sensory neurons of DRG are critical for neuropathic pain genesis. DNA methyltransferase (DNMT)-triggered DNA methylation silences gene expression. We show here that DNMT1, a canonical maintenance methyltransferase, acts as the de novo DNMT and is required for neuropathic pain genesis likely through repressing at least DRG Kcna2 gene expression in male mice. Peripheral nerve injury upregulated DNMT1 expression in the injured DRG through the transcription factor cAMP response element binding protein-triggered transcriptional activation of Dnmt1 gene. Blocking this upregulation prevented nerve injury-induced DNA methylation within the promoter and 5' -untranslated region of Kcna2 gene, rescued Kcna2 expression and total Kv current, attenuated hyperexcitability in the injured DRG neurons, and alleviated nerve injury-induced pain hypersensitivities. Given that Kcna2 is a key player in neuropathic pain, our findings suggest that DRG DNMT1 may be a potential target for neuropathic pain management.
\end{abstract}

Key words: DNMT1; DRG; epigenetic mechanisms; Kv1.2; neuropathic pain

Significance Statement

In the present study, we reported that DNMT1, a canonical DNA maintenance methyltransferase, is upregulated via the activation of the transcription factor CREB in the injured DRG after peripheral nerve injury. This upregulation was responsible for nerve injury-induced de novo DNA methylation within the promoter and 5' -untranslated region of the Kcna2 gene, reductions in Kcna2 expression and Kv current and increases in neuronal excitability in the injured DRG. Since pharmacological inhibition or genetic knockdown of DRG DNMT1 alleviated nerve injury-induced pain hypersensitivities, DRG DNMT1 contributes to neuropathic pain genesis partially through repression of DRG Kcna2 gene expression.

\section{Introduction}

Peripheral nerve injury-induced neuropathic pain is a complex and debilitating public health concern. Current successful treatment options for this disorder are limited (Campbell and Meyer, 2006). Although opioids are the last option for pharmacological treatment of neuropathic pain, they cause severe side effects (Coluzzi and Pappagallo, 2005; Jongen et al., 2013). Particularly,

\footnotetext{
Received March 27, 2019; revised May 30, 2019; accepted June 3, 2019.

Author contributions: L.S., X. Gu, Z.P., J.L., F.E.A., S.W., and Y.-X.T. designed research; L.S., X. Gu, Z.P., X. Guo, J.L., F.E.A., S.W., K.M., B.X., and L.L. performed research; L.S., X. Gu, Z.P., X. Guo, A.B., and Y.-X.T. analyzed data; L.S. wrote the first draft of the paper; L.S., X. Gu, and Y.-X.T. edited the paper; L.S. and Y.-X.T. wrote the paper.

This work was supported by National Institutes of Health Grants NS094664, NS094224, and DA033390 to Y.-X.T. The authors declare no competing financial interests.

*L.S. and X. Gu contributed equally to this work.

Correspondence should be addressed to Yuan-Xiang Tao at yuanxiang.tao@njms.rutgers.edu.

https://doi.org/10.1523/JNEUROSCI.0695-19.2019

Copyright $\odot 2019$ the authors
}

the increase in opioid prescriptions recently in the United States has been accompanied by a huge increase in the incidence of addiction and opioid-related mortality (Meyer et al., 2014). Thus, identifying the mechanisms of neuropathic pain is essential for the discovery of novel treatments and preventative tactics for the disorder. Nerve injury-induced transcriptional changes in gene expression of ion channels, receptors, enzymes, and cytokines/chemokines in the DRG contribute to neuropathic pain genesis (Campbell and Meyer, 2006; Latremoliere and Woolf, 2009; Lutz et al., 2014; Liang et al., 2015; Wu et al., 2016). However, the mechanisms underlying these changes remain elusive.

DNA methylation represses gene expression (Poetsch and Plass, 2011; Liang et al., 2015). DNA methylation is catalyzed primarily by a family of DNA methyltransferases (DNMTs), including DNMT1, DNMT3a, and DNMT3b. Conventionally, DNMT3a and DNMT3b function as de novo DNMTs to revers- 
ibly methylate unmethylated DNA, whereas DNMT1 is classified as the primary DNMT to maintain DNA methylation that has been established at the genome (Jeltsch, 2006; Siedlecki and Zielenkiewicz, 2006). The contribution of de novo DNMT3atriggered DNA methylation to neuropathic pain genesis was reported (Miao et al., 2017; Shao et al., 2017; Sun et al., 2017; Xu et al., 2017; Zhao et al., 2017; Mo et al., 2018; Mao et al., 2019; Yuan et al., 2019). Expression of DNMT3a, but not DNMT3b, is increased in the injured DRG following peripheral nerve injury (Zhao et al., 2017). Blocking this increase via genetic knockdown of DRG DNMT3a ameliorated neuropathic pain, likely through reducing nerve injury-induced increase of DNA methylation in the promoter regions of the Oprm1 (encoding mu opioid receptor, MOR) and Kcna2 (encoding Kv1.2) genes and consequently rescuing downregulation of their mRNAs in the injured DRG (Sun et al., 2017; Zhao et al., 2017). Mimicking nerve injuryinduced increase in DRG DNMT3a led to neuropathic pain-like symptoms (Zhao et al., 2017). The evidence also indicates that DNMT1, like DNMT3a, might also have de novo methylation activity. Residual DNA methylation was observed in Dnmt3al Dnmt3b double KO embryos (Okano et al., 1999). Unmethylated reporter DNA introduced into Dnmt3a/Dnmt3b double KO cells acquired some de novo methylation (Lorincz et al., 2002). In addition, overexpression of DNMT1 could create detectable de novo DNA methylation activity toward both preexisting methylated DNA substrates (Tollefsbol and Hutchison, 1997; Fatemi et al., 2001) and unmethylated DNA substrates (Pradhan et al., 1999; Vilkaitis et al., 2005). Whether DNMT1, like DNMT3a, in the DRG participates in neuropathic pain remains elusive.

We report here that DRG DNMT1 is required for neuropathic pain genesis, possibly through elevating DNA methylation within the Kcna2 promoter and $5^{\prime}$-untranslated regions, decreasing Kcna2 expression and total $\mathrm{Kv}$ current, and increasing neuronal excitability in the injured DRG. DNMT1 likely is a potential therapeutic target in the management of neuropathic pain.

\section{Materials and Methods}

Animals. All animals were kept in a controlled $12 \mathrm{~h}$ light/dark cycle (light 7:00 A.M. to 7:00 P.M., dark 7:00 P.M. to 7:00 A.M.), with free access to water and food pellet. Eight- to 10-week-old male C57BL/6J mice were used for pain behavior tests. All procedures performed were in accordance with the Animal Care \& Use Committee at Rutgers, the State University of New Jersey, the National Institutes of Health, and the International Association for the Study of Pain. To address the role of Dnmt1 specifically within sensory neurons, we generated conditional KO mice. Mice bearing Dnmt1 with two LoxP sites flanking exon 3, termed as $D n m t 1^{f l f l}$, were a gift from Dr. Eric J Nestler (Icahn School of Medicine at Mount Sinai, New York). Mice bearing targeted knock-in of the Cre allele into the second exon of the Advillin gene, termed as Advillin-Cre $\left(A d v^{\text {cre }}\right)$, were a gift from from Dr. Fan Wang (Duke University Medical Center, Durham, NC). Female Dnmt $1^{f l f l}$ mice were fully crossed with male $A d v^{\text {cre }}$ mice to generate sensory neuron-specific conditional $\mathrm{KO}$ of Dnmt1 ( $\left.A d v^{\text {cre }} D n m t 1^{f l f l}\right)$ mice. Male litters were used in behavior tests.

Neuropathic pain models. Spinal nerve ligation (SNL) (Liang et al., 2016a), chronic constriction injury of sciatic nerve (CCI) (Li et al., 2017), and axotomy models (Fan et al., 2014) were performed as previously reported. Briefly, for the SNL model, the skin on the lower lumbar back region was prepared. A dorsolateral skin incision was then made on the lower back. The fifth lumbar transverse process was identified, freed of its muscle attachment, and then removed. The underlying fourth lumbar spinal nerve (including sensory and motor fibers) was isolated, ligated with nonabsorbable suture, and transected just distal to the ligature. For the CCI model, the skin on the lateral surface of the high thigh level was prepared. A skin incision and blunt dissection were made to expose the sciatic nerve trunk above the femoral joint. Three loose ligations were made, $1 \mathrm{~mm}$ apart with nonabsorbable thread, to the sciatic nerve. For the axotomy model, the exposed sciatic trunk was transected. In all sham-operated controls, the identified surgery was performed without ligation of spinal nerve or sciatic nerve.

Behavioral tests. Mechanical, thermal, and cold behavioral tests were performed in each mouse to monitor its paw withdrawal responses ( $\mathrm{Li}-$ ang et al., 2016b). The tests were conducted with $1 \mathrm{~h}$ intervals between each test. The experimenter who performed these behavioral tests was blind to the group allocations of the mice.

For the mechanical test, mice were put in separate plastic chambers on an elevated mesh floor and allowed $30 \mathrm{~min}$ for habituation before the test. Two calibrated von Frey filaments $(0.07$ and $0.4 \mathrm{~g}$ ) were applied to the plantar surface of each hindpaw 10 times, respectively. A quick withdrawal of the paw was considered as a positive response. The number of positive responses of 10 stimuli was recorded as percentage withdrawal frequency [(number of paw withdrawals $/ 10$ trials $) \times 100=$ percentage response frequency]. For Hargreaves' thermal test, mice were prepared as the same way as for the mechanical test. The plantar surface of each hindpaw was exposed to a beam of radiant heat underneath the glass plate. Intensity was adjusted to obtain baseline paw withdrawal latencies between 8 and $10 \mathrm{~s}$ in WT mice. The latencies were averaged over three trials, separated by a $10 \mathrm{~min}$ interval. A cutoff time of $20 \mathrm{~s}$ was set to prevent potential heat injury. For the cold plate test, an aluminum plate was precooled and maintained at a constant $0^{\circ} \mathrm{C}$, which was continuously monitored using a thermometer. Each animal was then placed in a Plexiglas chamber on the cold plate. The time length between initial paw contact with the plate and paw withdrawal from the plate was defined as the paw withdrawal latency. The latencies were averaged over three trials, separated by a $10 \mathrm{~min}$ interval. A cutoff time of $20 \mathrm{~s}$ was set to prevent potential cold injury.

Functional locomotor activities in mice were assessed through three reflex tests as previously described (Li et al., 2017; Mo et al., 2018). (1) Placing reflex: The mice were held with the hind limbs slightly lower than the forelimbs, and the dorsal surfaces of the hindpaws were brought into contact with the edge of a table. The experimenters observed whether the hindpaws were placed on the table surface reflexively. (2) Grasping reflex: The mice were placed on a wire grid, and the experimenters noted whether the hindpaws grasped the wire on contact. (3) Righting reflex: The mice were placed with their back on an even surface, and the experimenters recorded whether they immediately resumed the normal upright position. Each reflex was checked in five consecutive trials. Scores for placing, grasping, and righting reflexes were based on counts of normal reflexes.

$D R G$ microinjection. To specifically knock down DNMT1 only in L4 DRG, adult male Dnmt $1^{f l f l}$ mice received microinjection with adenoassociated virus (AAV) vectors (serotype 5) expressing Cre recombinase, termed as AAV5-Cre (University of North Carolina Vector Core), into unilateral L4 DRG. AAV5-GFP virus served as the controls. DRG microinjection was performed as described previously (Liang et al., 2016b). Briefly, unilateral L4 DRG was exposed, and the viral solution $(1 \mu \mathrm{l}$, titer $\geq 1 \times 10^{12} / \mathrm{ml}$ ) was injected into the DRG over a period of $10 \mathrm{~min}$. The glass micropipette was left in place for $10 \mathrm{~min}$ after the injection. The mice revealing signs of paresis or other abnormalities were excluded.

Drug administration. RG108, a novel DNMT1 inhibitor (Asgatay et al., 2014; Dong et al., 2019), with relatively low cytotoxic or genotoxic effects compared with five other DNMT inhibitors (5-aza-CR, 5-azaCdR, zebularine, procaine, and epigallocatechin-3-gallate) were used. RG108 (Tocris Bioscience) was given intraperitoneally at $0.4 \mathrm{mg} / \mathrm{kg}$ once a day for $7 \mathrm{~d}$. Mechanical, thermal, and cold behavioral tests with $1 \mathrm{~h}$ intervals between each test were performed $1 \mathrm{~d}$ before RG108 injection and 30 min after RG108 injection on days 3, 5, and 7 after SNL.

Plasmid construction and viral production. The pcDNA3.1(-) plasmid harboring mouse CCAAT/enhancer-binding protein $\beta(\mathrm{C} / \mathrm{EBP} \beta)$ was a gift from Prof. Xi Li at Fudan University, China. After the plasmid was digested by $\mathrm{XbaI} / \mathrm{BamHI}$, full-length $\mathrm{C} / \mathrm{EBP} \beta \mathrm{cDNA}$ was gel purified and ligated into proviral plasmids (Li et al., 2017). Mouse cAMP response element binding protein (CREB) cDNA was synthesized and amplified from the total RNA of mouse DRG (Liang et al., 2016a). Fragments bearing full-length CREB were ligated into proviral plasmids (University 
of North Carolina Vector Core) using the BspEI and NotI restriction sites (New England Biolabs) driven by the cytomegalovirus promoter. Packaging of the rAAV5 viral particles encoding the respective plasmids was performed by the University of North Carolina Vector Core. Construction and packaging of AAV5-myeloid zinc finger 1 (MZF1) (Li et al., 2015) and AAV5-octamer transcription factor 1 (OCT1) 6 (Yuan et al., 2019) were described in our previous studies.

Immunohistochemistry. Mice were anesthetized with isoflurane and perfused with $4 \%$ PFA before being analyzed by double-labeled immunohistochemistry. L4 DRGs were dissected, postfixed, dehydrated, and frozen sectioned at $20 \mu \mathrm{m}$. After being blocked for $1 \mathrm{~h}$ at room temperature in $0.01 \mathrm{M}$ PBS containing $10 \%$ goat serum and $0.3 \%$ Triton X-100, the sections were further incubated overnight at $4^{\circ} \mathrm{C}$ with rabbit antiDNMT1 (1:600, Abcam) plus mouse anti-neurofilament-200 (NF200, 1:500, Sigma-Aldrich), isolectin B4 (IB4, 1:100, Santa Cruz Biotechnology), mouse anti-calcitonin gene-related peptide (CGRP, 1:50, Abcam), mouse anti-NeuN (1:50, GeneTex), or mouse anti-glutamine synthetase (GS, 1:500, EMD Millipore). The sections were then incubated with goat anti-rabbit antibody conjugated to Cy3 (1:200, Jackson ImmunoResearch Laboratories), goat anti-mouse antibody conjugated to Cy2 (1: 200, Jackson ImmunoResearch Laboratories), or avidin labeled with FITC (1:200, Sigma-Aldrich, A2050) for $2 \mathrm{~h}$ with vigorous shaking at room temperature. Control experiments for rabbit anti-DNMT1 included substitution of normal rabbit serum for the primary antiserum, omission of the primary antiserum, and preabsorption of the primary antibody with overdose of the antigen. The specificity of remaining primary antisera has been identified previously (Miao et al., 2017; Shao et al., 2017; Sun et al., 2017; Xu et al., 2017; Zhao et al., 2017; Mo et al., 2018; Mao et al., 2019; Yuan et al., 2019). The sections finally mounted using VectaMount permanent mounting medium (Vector Laboratories) or Vectashield plus DAPI mounting medium (Vector Laboratories). Immunofluorescence-labeled images were captured using a Leica Microsystems DMI4000 fluorescence microscope with a DFC365FX camera (Leica Microsystems). Double-labeled neurons were quantified by NIH ImageJ Software.

Cell culture and transfection. Primary DRG cultures were prepared from 3- to 4-week old WT C57BL/6J, Dnmt fl/fl or $A d v^{\text {cre } D n m t ~} 1^{f l / f l}$ mice. After mice were killed with isoflurane, all DRGs were collected in cold Neurobasal medium (Invitrogen) with 10\% FBS (JR Scientific), 100 units/ml penicillin, and $100 \mu \mathrm{g} / \mathrm{ml}$ streptomycin (Quality Biological). Then, they were treated with enzyme solution [dispase $(5 \mathrm{mg} / \mathrm{ml})$, collagenase Type I $(1 \mathrm{mg} / \mathrm{ml})$ in Hanks' balanced salt solution without $\mathrm{Ca}^{2+}$ and $\mathrm{Mg}^{2+}$ (Invitrogen)]. After trituration and centrifugation, dissociated cells were resuspended in mixed neurobasal medium and plated in a six-well plate coated with poly-D-lysine ( $50 \mu \mathrm{g} / \mathrm{ml}$, Sigma-Aldrich). The cells were incubated at $95 \% \mathrm{O}_{2}, 5 \% \mathrm{CO}_{2}$, and $37^{\circ} \mathrm{C}$ for $24 \mathrm{~h}$ before transfection. A volume of $2 \mu \mathrm{l}$ of AAV5 virus (titer $\geq 1 \times 10^{12} / \mathrm{ml}$ ) was added to the culture. Cells were harvested $48-72 \mathrm{~h}$ later for Western blot or qRT-PCR assay.

Western blot assay. Two L4 DRGs from two individual mice were pooled together for Western blot assay. Protein samples were prepared and loaded onto a $4 \%-15 \%$ stacking $/ 7.5 \%$ separating SDS-polyacrylamide gel (Bio-Rad, 345-0032) as reported previously (Liang et al., 2016a). The proteins on the gel were then electrophoretically transferred onto a PVDF membrane (Bio-Rad, 162-0233). Membranes were blocked with $3 \%$ nonfat milk in TBS containing $0.1 \%$ Tween 20 , pH 7.40, for $1 \mathrm{~h}$ at room temperature. The following primary antibodies were used: rabbit anti-DNMT1 (1:500, Cell Signaling Technology), rabbit anti-DNMT3a (1:500, Cell Signaling Technology), rabbit anti-DNMT3b (1:500, Cell Signaling Technology), mouse anti-Kv1.2 (1:200, NeuroMab), mouse anti-Kv1.4 (1:200, NeuroMab), mouse anti-Nav1.7 (1: 1000; NeuroMab), rabbit anti-MOR (1:500, Neuromics), rabbit anti- $\kappa$ opioid receptor ( $\kappa$ opioid receptor [KOR], 1:500, Novus Biologicals), rabbit anti-CREB (1:1000, Abcam), mouse anti-phospho-CREB (Ser133) (1:1000, EMD Millipore); mouse anti-C/EBP $\beta$ (1:500, Abcam), rabbit anti-MZF1 (1:200, gift from Dr D.Y.H. Tuan, Georgia Regents University), rabbit anti-OCT1 (1:500, Abcam), rabbit anti-GAPDH (1: 1000, Santa Cruz Biotechnology), and rabbit anti-histone H3 (1:1000, Cell Signaling Technology). The specificity of rabbit anti-DNMT1 was examined in the following control experiments, including substitution of normal rabbit serum for the primary antiserum, omission of the primary antiserum, and preabsorption of the primary antibody with overdose of the antigen. The specificity of remaining primary antisera was reported previously (Lee et al., 2011; Zhao et al., 2013, 2017; Fan et al., 2014; Li et al., 2015, 2017; Sun et al., 2017; Mo et al., 2018; Du et al., 2019; Mao et al., 2019) or from vendors' data sheets. Membranes were further incubated with anti-mouse or anti-rabbit HRP-conjugated secondary antibody (1: 3000, Jackson ImmunoResearch Laboratories) for $2 \mathrm{~h}$ at room temperature and visualized by Western peroxide reagent and luminol/enhancer reagent (Clarity Western ECL Substrate, Bio-Rad). Images were generated with the ChemiDoc XRS System with Image Lab software (Bio$\mathrm{Rad})$. Intensities of protein bands were quantified using the Image Lab software. Values of cytosolic proteins were normalized to those of GAPDH and nucleus proteins to histone H3.

$q R T-P C R$ assay. DRGs from 4 individual mice were pooled together to achieve enough RNA. RNA was precipitated, treated with DNase I, and reverse-transcribed to cDNA using the ThermoScript reverse transcriptase (Invitrogen), random hexamers, oligo (dT) primers or specific RT-primers (Fig. 2-1, available at https://doi.org/10.1523/ JNEUROSCI.0695-19.2019.f2-1); 100 ng of each cDNA was prepared in quadruplicate in $20 \mu \mathrm{l}$ reaction solution $[0.1 \mathrm{M}$ of each primer, and $1 \times$ SYBR PCR Master Mix (Bio-Rad, 172-5274)] and then amplified by real-time PCR (Applied Biosystems) using the primers listed in Fig. 2-1 (available at https://doi.org/10.1523/JNEUROSCI.0695-19.2019.f2-1). Ratios of ipsilateral-side mRNA levels to contralateral-side mRNA levels were calculated using the $\Delta \mathrm{Ct}$ method $\left(2^{-\Delta \Delta \mathrm{Ct}}\right)$. All data were normalized to Gapdh, which has been demonstrated to be stable even after peripheral nerve injury insult (Zhao et al., 2013).

Single-cell RT-PCR assay. Primary DRG culture from C57BL/6J mice was performed as described above. Four hours after plating, small $(<15$ $\mu \mathrm{m}$ in diameter), medium (15-35 $\mu \mathrm{m}$ in diameter), and large ( $>35 \mu \mathrm{m}$ in diameter) DRG neurons were collected individually with a glass micropipette under an inverted microscope fit with a micromanipulator and microinjector, and placed in individual PCR tubes with $10 \mu \mathrm{l}$ of cDNA cell lysis buffer (Signosis). After centrifugation, the supernatants were collected. Real-time RT-PCR procedure was performed as described above using the primers listed in Fig. 2-1 (available at https:// doi.org/10.1523/JNEUROSCI.0695-19.2019.f2-1).

Chromatin immunoprecipitation (ChIP) assay. ChIP assays were conducted using the EZ ChIP Kit (Millipore, 17-371), following the manufacturer's instructions. After DRGs from 5 individual mice were homogenized, the proteins were then crosslinked with DNA by adding formaldehyde (a final concentration of $1 \%$ ) for $10 \mathrm{~min}$ at room temperature. The cross-linking reaction was quenched by adding $0.125 \mathrm{M}$ glycine solution for $5 \mathrm{~min}$ at room temperature. The sample was then suspended in SDS lysis buffer containing $1 \times$ protease inhibitor mixture (Millipore) and sonicated to yield fragments of $500 \mathrm{bp}$ average size. After centrifugation, the supernatant was collected and precleared with protein $\mathrm{G}$ agarose beads for $1 \mathrm{~h}$ at $4^{\circ} \mathrm{C}$ with agitation; $5 \%$ of the soluble chromatin fraction was applied for input normalization. A total of $2 \mu \mathrm{g}$ of rabbit anti-CREB (Abcam), rabbit anti-DNMT1 (Abcam), or rabbit IgG was added into the remaining soluble chromatin fraction and incubated overnight at $4^{\circ} \mathrm{C}$ with rotation. Immune complexes were pulled down with $60 \mu \mathrm{l}$ of protein $\mathrm{G}$ agarose beads for $1 \mathrm{~h}$ at $4^{\circ} \mathrm{C}$. The agarose beads were then washed and eluted. After the cross-linking was completely reversed by overnight incubation at $65^{\circ} \mathrm{C}$, the proteins were then digested with proteinase $\mathrm{K}$ for $2 \mathrm{~h}$ at $45^{\circ} \mathrm{C}$. The DNA was recovered, purified, and amplified using real-time PCR with primers listed in Fig. 2-1 (available at https://doi.org/ 10.1523/JNEUROSCI.0695-19.2019.f2-1).

DNA methylation analysis. The ipsilateral L4 DRG was collected for DNA extraction. Genomic DNA was bisulfite-converted using EZ DNA Methylation-Lighting Kit (Zymo Research) according to the manufacturer's instructions. Bisulfite primers listed in Fig. 2-1 (available at https://doi.org/10.1523/JNEUROSCI.0695-19.2019.f2-1) were designed to amplify the specific region of Kcna2 promoter with differential binding by DNMT1. The PCR program was run at $94^{\circ} \mathrm{C}$ for $2 \mathrm{~min} ; 6$ cycles of $94^{\circ} \mathrm{C}$ for $15 \mathrm{~s}, 53^{\circ} \mathrm{C}$ for $20 \mathrm{~s}, 72^{\circ} \mathrm{C}$ for $30 \mathrm{~s}$; then 33 cycles of $94^{\circ} \mathrm{C}$ for $15 \mathrm{~s}$, $56^{\circ} \mathrm{C}$ for $20 \mathrm{~s}, 72^{\circ} \mathrm{C}$ for $30 \mathrm{~s}$; followed by $72^{\circ} \mathrm{C}$ for $3 \mathrm{~min}$. PCR products 

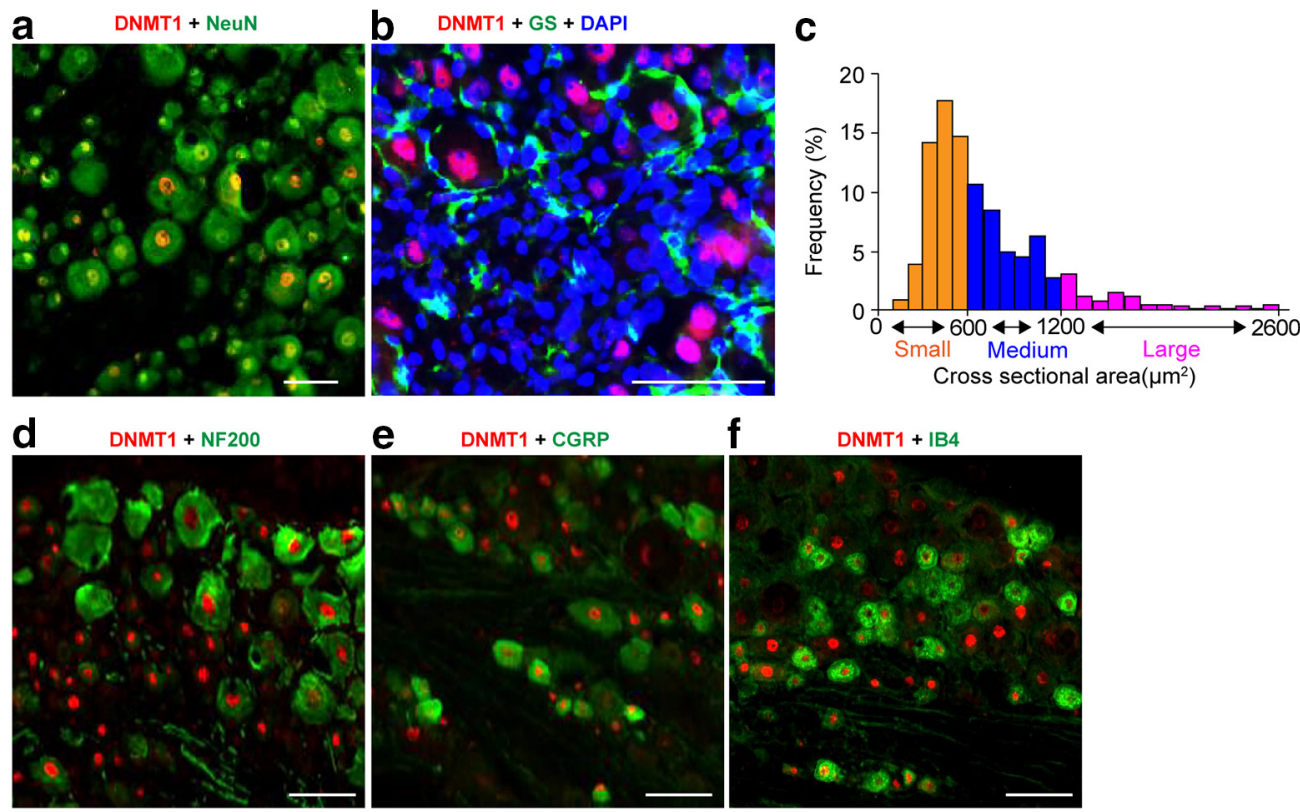

Figure 1. Expression and distribution of DNMT1 protein in lumbar DRG of naive mice. $\boldsymbol{a}, \boldsymbol{b}$, DNMT1 (red) is coexpressed exclusively in NeuN (green) in cellular nuclei ( $\boldsymbol{a}$ ) and undetected in cellular nuclei (labeled by DAPI) of GS (green)-labeled cells (b). c, Distribution of DNMT1-positive somata: small, 51.55\%; medium, 37.77\%; large, 10.68\%. $\boldsymbol{d}$-f, DNMT1-positive neurons were labeled by NF200 (d, green), CGRP (e, green), or IB4 ( $\boldsymbol{f}$, green). $n=5$ mice. Scale bars, $40 \mu \mathrm{m}$. Validation of the DNMT1 antibody specificity is shown in Figure 1-1, available at https://doi.org/10.1523/ JNEUROSCI.0695-19.2019.f1-1.

were purified using the Gel PCR purification Kit (Invitrogen), then cloned using TOPO TA Cloning Kit (450030, Invitrogen). After an overnight bacterial culture, 20 subclones from each PCR assay were subjected to direct sequencing.

Whole-cell patch recording. The acutely dissociated mouse L4 DRG neurons from 6- to 8-week-old mice were prepared as described previously (Liang et al., 2016a) to record potassium currents in DRG neurons. Briefly, whole-cell patch-clamp recording was performed $4-12 \mathrm{~h}$ after DRG neuron plating. The electrode resistance of micropipettes ranged from 3 to $5 \mathrm{~m} \Omega$. Cells were voltage-clamped with an Axopatch-700B amplifier (Molecular Devices). The intracellular pipette solution contained the following (in $\mathrm{mm}$ ): 120 potassium gluconate, $20 \mathrm{KCl}, 2 \mathrm{MgCl}_{2}$, 10 EGTA, 10 HEPES, and $4 \mathrm{Mg}$-ATP, pH 7.3 (with $\mathrm{KOH}, 310 \mathrm{mOsm}$ ). The extracellular solution contained the following (in $\mathrm{mM}$ ): 150 choline chloride, $5 \mathrm{KCl}, 1 \mathrm{CdCl}_{2}, 2 \mathrm{CaCl}_{2}, 1 \mathrm{MgCl}_{2}, 10 \mathrm{HEPES}$, and 10 glucose, $\mathrm{pH} 7.4$ (with Tris base, $320 \mathrm{mOsm}$ ). Series resistance was compensated by $60 \%-80 \%$. An online $\mathrm{P} / 4$ leak subtraction was performed to eliminate leak current contribution. The data were stored on the computer by a DigiData 1550 interface and analyzed by the pCLAMP 10.4 software package (Molecular Devices).

The current-clamp recording was performed to record action potential (AP) at room temperature $\left(\sim 20^{\circ} \mathrm{C}-23^{\circ} \mathrm{C}\right)$. The extracellular solution contained the following (in mM): $140 \mathrm{NaCl}, 4 \mathrm{KCl}, 2 \mathrm{CaCl}_{2}, 2 \mathrm{MgCl}_{2}, 10$ HEPES, and 5 glucose, with $\mathrm{pH}$ adjusted to 7.38 by $\mathrm{NaOH}$. The intracellular pipette solution contained the following (in $\mathrm{mm}$ ): $135 \mathrm{KCl}, 3 \mathrm{Mg}$ ATP, $0.5 \mathrm{Na}_{2} \mathrm{ATP}, 1.1 \mathrm{CaCl}_{2}, 2 \mathrm{EGTA}$, and 5 glucose, $\mathrm{pH}$ adjusted to 7.38 with $\mathrm{KOH}$ and osmolarity adjusted to $300 \mathrm{mOsm}$ with sucrose. The resting membrane potential was taken $3 \mathrm{~min}$ after a stable recording was first obtained. The DRG neurons with resting membrane potentials more hyperpolarized than $-40 \mathrm{mV}$ were chosen. The neurons were excluded from the analysis if leak currents were $>150 \mathrm{pA}$ at $-80 \mathrm{mV}$, access resistance $>5 \%$ of the input resistance, input resistance $<200 \mathrm{M} \Omega$, or if any of these parameters changed by $>20 \%$ during the recording. The membrane potential was held at the existing resting membrane potential during the current injection. The depolarizing currents from 100 to 1400 $\mathrm{pA}$ (100 pA increment, $200 \mathrm{~ms}$ duration) were delivered to evoke AP. The AP threshold was defined as the first point on the rapid rising phase of the spike at which the change in voltage exceeded $50 \mathrm{mV} / \mathrm{ms}$. The AP amplitude was measured between the peak and the baseline. The AP overshoot was measured between the AP peak and $0 \mathrm{mV}$. The membrane input resistance was measured by delivering a series of hyperpolarizing currents from $200 \mathrm{pA}$ to $-2000 \mathrm{pA}$ (200 ms duration, $100 \mathrm{pA}$ step) and obtained from the slope of a steady-state $I-V$ plot. The afterhyperpolarization amplitude was measured between the maximum hyperpolarization and the final plateau voltage. The neurons were excluded for AP analysis if the injected current to evoke a spike was $>1000 \mathrm{pA}$. The data were stored on computer by a DigiData 1500 interface and analyzed by the pCLAMP 10.4 software package (Molecular Devices). All experiments were performed at room temperature.

Statistical analysis. All of the results are given as mean \pm SEM. The data were statistically analyzed with two-tailed, paired or unpaired Student's $t$ test and one-way or two-way ANOVA. When ANOVA showed a significant difference, pairwise comparisons between means were tested by the post hoc Turkey method (Sigma-Aldrich, Plot 12.5). Significance was set at $p<0.05$.

\section{Results}

Distribution of DNMT1 in the DRG

We first analyzed the expression and distribution pattern of DNMT1 in the DRG. Using double labeling for DNMT1 and NeuN (a marker for neurons) or triple labeling for DNMT1, GS (a marker for satellite glial cells), and DAPI (a marker for cellular nuclei), we reported that DNMT1 was colocalized with NeuN in cellular nuclei (Fig. 1a) and was not seen in the cellular nuclei of the GS-positive cells (Fig. 1b). No staining was detected after substitution of normal rabbit serum or omission/preabsorption of the primary antibody (Fig. 1-1, available at https://doi.org/ 10.1523/JNEUROSCI.0695-19.2019.f1-1). Approximately 48.5\% of the NeuN-labeled neurons (706 of 1455) were positive for DNMT1. A cross-sectional analysis of cell-size distribution showed that $\sim 51.55 \%$ of the DNMT1-labeled neurons were small $\left(<600 \mu \mathrm{m}^{2}\right), 37.77 \%$ were medium $\left(600-1200 \mu \mathrm{m}^{2}\right)$, and $10.68 \%$ were large $\left(>1200 \mu \mathrm{m}^{2}\right.$; Fig. 1 c). Subpopulation analysis showed that $\sim 33.45 \%$ of the DNMT1-labeled neurons were positive for NF200 (a marker for medium/large neurons and myelinated A $\beta$-fibers; Fig. $1 d$ ), $42.16 \%$ for CGRP (a marker for small 

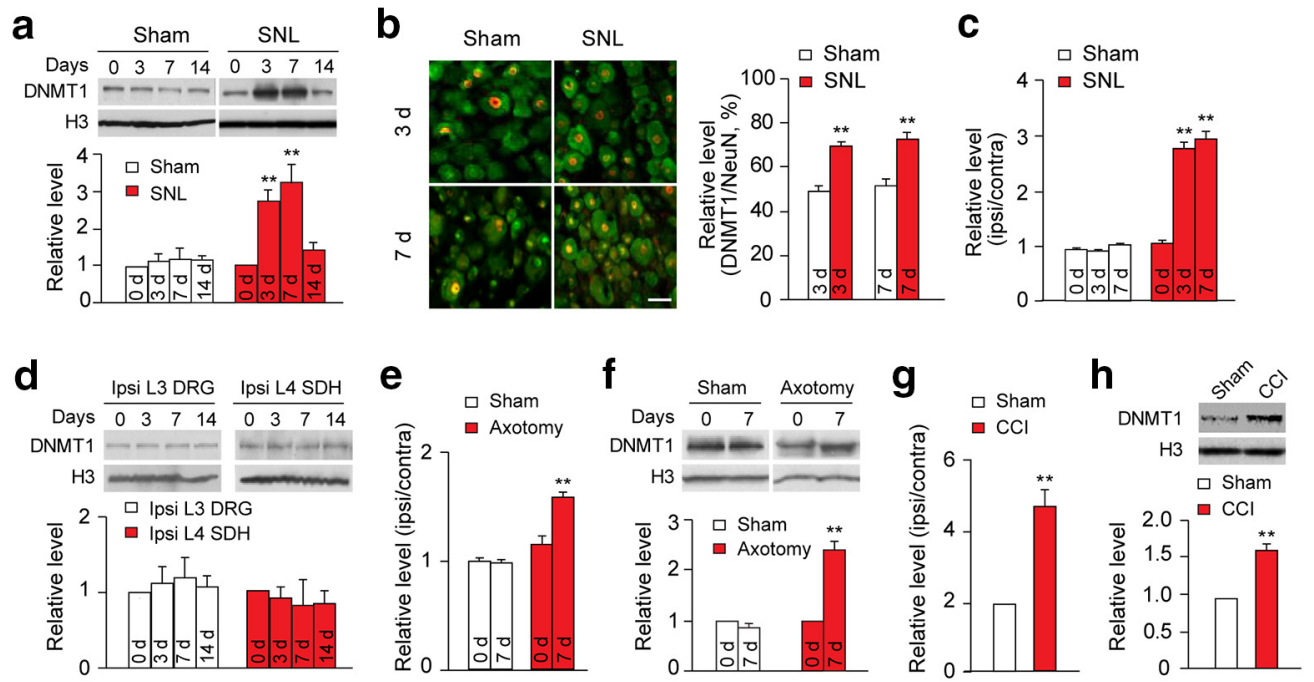

Figure 2. Peripheral nerve injury upregulates Dnmt1 mRNA and protein in the injured DRG of mice. $\boldsymbol{a}$, DNMT1 protein expression in the ipsilateral L4 DRGs after SNL or sham surgery. $n=4$ mice/group/time point. Two-way ANOVA followed by post hoc Tukey test: $F_{\text {time }}(3,24)=10.46 ; F_{\text {model }}(1,24)=41.44 .{ }^{* *} p<0.01$ versus the corresponding control group $(0 \mathrm{~d}) \cdot \boldsymbol{b}$, Representative immunostaining images (left) of the neurons labeled by DNMT1 (red) and NeuN (green) and a summary of analysis on the number of DNMT1-labeled neurons (right) in the ipsilateral L 4 DRG on days 3 and 7 after SNL and sham surgery. $n=2$ mice/group/time point. Two-way ANOVA followed by post hoc Tukey test: $F_{\text {model }}(1,44)=1.112 .{ }^{* *} p<0.01$ SNL versus sham. c, Dnmt $1 \mathrm{mRNA}$ expression in the ipsilateral L4 DRG on days 3 and 7 after SNL or sham surgery. $n=6$ mice/group/time point. Two-way ANOVA followed by post hoc Tukey test: $F_{\text {time }}(2,17)=79.56$. ${ }^{* *} p<0.01$ versus the corresponding control group ( $0 \mathrm{~d}$ ). d, DNMT1 protein expression in the ipsilateral (Ipsi) L3 DRG and L4 spinal cord dorsal horn (DH) on days 3 and 7 after SNL. $n=4$ mice/group/time point. One-way ANOVA followed by post hoc Tukey test: $F_{\text {time }}(3,12)=0.21$ for ipsi L3 DRGs; $F_{\text {time }}(3,12)=0.16$ for ipsi L4 SDH. $\boldsymbol{e}, \boldsymbol{f}$, Expressions of Dnmt $1 \mathrm{mRNA}(\boldsymbol{e})$ and protein $(\boldsymbol{f})$ in the ipsilateral L3/4 DRGs on day 7 after axotomy or sham surgery. $n=6$ mice/group/time point. Two-way ANOVA followed by post hoc Tukey test: $F_{\text {time }}(1,12)=17.5$ in $\boldsymbol{e} ; F_{\text {time }}(1,12)=42.72$ in $f$. ${ }^{* *} p<0.01$ versus the corresponding control group $(0 \mathrm{~d}) \cdot \boldsymbol{g}, \boldsymbol{h}$, Expressions of Dnmt $1 \mathrm{mRNA}(\boldsymbol{g})$ and protein $(\boldsymbol{h})$ in the ipsilateral L3/4 DRGs on day 7 after CCl or sham surgery. $n=3$ mice/group. ${ }^{* *} p<0.01$ versus the corresponding control group ( $0 \mathrm{~d}$ ) (two-tailed unpaired Student's $t$ test). Primer sequences are provided in Figure 2-1, available at https://doi.org/10.1523/JNEUROSCI.0695-19.2019.f2-1.

DRG peptidergic neurons; Fig. 1e), and 34.98\% for IB4 (a marker for small nonpeptidergic neurons; Fig. $1 f$ ).

\section{DNMT1 is upregulated in the injured DRG following peripheral nerve injury}

We further asked whether DNMT1 expression was altered in DRG after peripheral nerve injury. DNMT1 was time-dependently and significantly upregulated in the ipsilateral (injured) L4 DRG after the unilateral L4 SNL, but not after sham surgery (Fig. $2 a)$. The levels of DNMT1 protein were increased by 2.8 -fold on day 3 ( $p<0.01$ ), 3.3-fold on day 7 ( $p<0.01$ ), and 1.5-fold on day $14(p>0.05)$ after SNL compared with naive mice (Fig. $2 a)$. The number of DNMT1-labeled neurons in the injured DRG on days 3 and 7 after SNL also increased by $21 \%(p<0.01)$ and $23 \%(p<$ $0.01)$, respectively, compared with the corresponding sham group (Fig. 2b). Furthermore, compared with naive mice, SNL (but not sham surgery) led to a significant increase in the amount of Dnmt 1 mRNA in the injured DRG on days 3 and 7 after surgery $(p<0.01$; Fig. $2 c)$. SNL did not alter basal expression of DNMT1 protein in the ipsilateral (intact) L3 DRG and ipsilateral L4 spinal cord dorsal horn (Fig. $2 d$ ). Similar results were found after axotomy and CCI to the unilateral sciatic nerve. The levels of DNMT1 mRNA and protein were increased by 1.6 -fold $(p<$ 0.01 ; Fig. $2 e$ ) and 2.4 -fold ( $p<0.01$; Fig. $2 f)$, respectively, on day 7 after axotomy compared with the corresponding naive mice and by 4.7 -fold ( $p<0.01$; Fig. $2 g$ ) and 1.7-fold ( $p<0.05$; Fig. $2 h$ ), respectively, on day 7 after CCI compared with the corresponding sham group. Collectively, our data revealed that DNMT1 was dramatically upregulated during the early period after peripheral nerve injury, which suggests that DNMT1 contributes to the development of nerve injury-induced neuropathic pain.
CREB transcriptionally activates DRG Dnmt1 gene after SNL How is DRG Dnmt1 gene transcriptionally activated after peripheral nerve injury? Transcription factors regulate gene expression. We used the online software TFSEARCH and found that potential binding motifs for at least four transcription factors (MZF1, OCT1, CEBP $\beta$ and CREB) were predicted within the promoter and 5-untranslated region of Dnmt1 gene. To screen which transcriptional factor affected DRG DNMT1 expression, we transduced AAV5 respectively expressing full-length of each of these four transcriptional factors into cultured DRG neurons. Overexpression of CREB, but not MZF1, OCT1, and CEBP $\beta$, markedly upregulated DNMT1 protein expression in DRG neurons (Fig. 3a; Fig. 3-1, available at https://doi.org/10.1523/JNEUROSCI.069519.2019.f3-1). A ChIP assay revealed that a fragment within the Dnmt1 gene promoter including a consensus CREB binding motif $\left(_{-366}\right.$ TGACGTCA $_{-359}$ ) could be amplified from the complex immunoprecipitated with CREB antibody, but not normal serum, in nuclear fractions from the DRGs of sham mice (Fig. 3b), suggesting the existence of specific binding of CREB to the Dnmt gene in DRG. Moreover, SNL produced a significant increase in the binding activity between CREB and Dnmt1 gene promoter, as evidenced by a 2.7 -fold increase in band density, in the injured DRG on day 7 after SNL ( $p<0.01$; Fig. $3 b)$. This increase may be attributed to the time-dependent increases in total CREB and its active form phosphorylated CREB (pCREB) in the injured DRG after SNL (Fig. 3c). Compared with the corresponding naive mice, SNL, but not sham surgery, elevated the level of pCREB by 1.8 -fold $(p<0.05)$ and 2.3-fold $(p<0.05)$ and the amount of total CREB by 1.5 -fold $(p>0.05)$ and 3.8 -fold $(p<0.05)$, respectively, on days 3 and 7 after surgery (Fig. $3 c$ ). As expected, neither SNL nor sham surgery changed basal expression of total CREB and pCREB in the contralateral L4 DRG, ipsilateral L3 

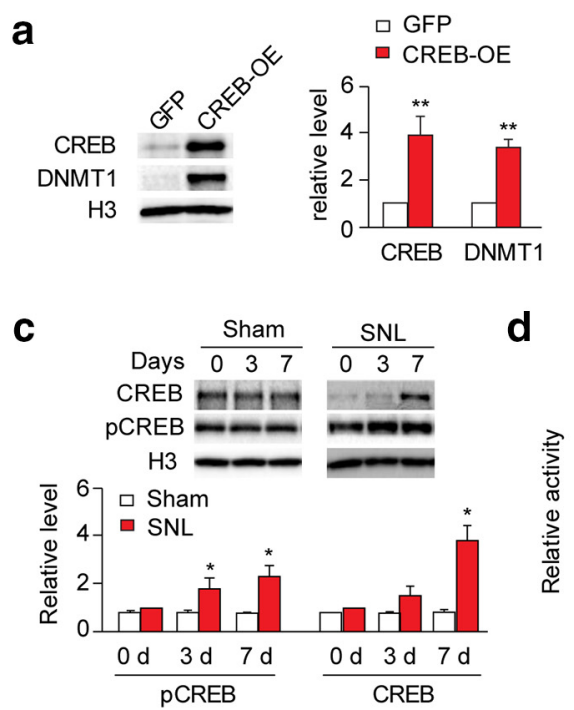
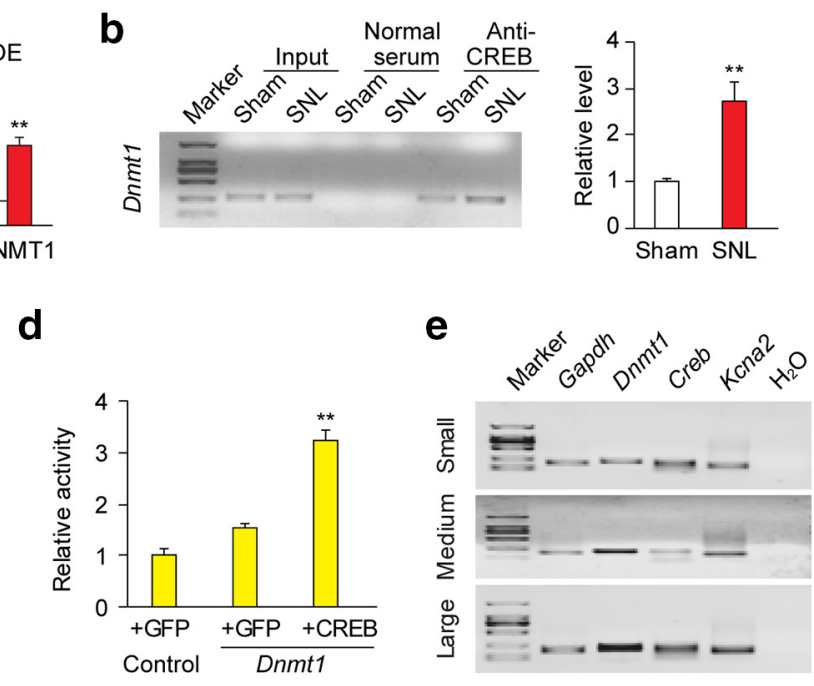

Figure 3. CREB transcriptionally activates Dnmt1 mRNA expression in the injured DRG after peripheral nerve injury. $\boldsymbol{a}$, CREB overexpression (0E) through AAV5-CREB (but not AAV5-GFP) transfection elevated DNMT1 expression in primary DRG-cultured neurons from mice. Left, Representative Western blots. Right, Summary of densitometric analysis. $n=3$ biological repeats/group. Two-tailed unpaired Student's $t$ test: ${ }^{* *} p<0.01$ versus the corresponding AAV5-GFP-treated group. $\boldsymbol{b}$, Binding activity between CREB and Dnmt 1 promoter region in the ipsilateral L4 DRG on day 7 after SNL or sham surgery. Left, Representative ChIP assay result. Right, Summary of quantitative PCR quantification analysis. $n=6$ mice/group. Two-tailed unpaired Student's $t$ test: ${ }^{* *} p<0.01$ versus sham group. $c$, Expression of (REB and its active form pCREB on days 3 and 7 after SNL or sham surgery. $n=6$ mice/group. Two-way ANOVA followed by post hoc Tukey test: $F_{\text {time }}$ ( 2,17$)=$ 10.13 for $p C R E B ; F_{\text {time }}(2,17)=9.85$ for CREB. ${ }^{*} p<0.05$ versus the corresponding control $(0 \mathrm{~d})$. $\boldsymbol{d}$, Dnmt1 gene promoter activity in HEK $293 \mathrm{~T}$-cells transfected with the vectors as indicated. $n=$ 3 biological repeats/group. One-way ANOVA followed by post hoc Tukey test: $F_{\text {group }}(2,8)=57.32$. ${ }^{* *} p<0.01$ versus the GFP plus control group. $e$, Coexpression of Creb mRNA with Dnmt 1 mRNA and Kcna 2 mRNA in individual small, medium, and large DRG neurons demonstrated by single-cell RT-PCR assay. $n=3$ biological repeats. Effect of DRG MZF1, 0CT1 and C/EBP $\beta$ overexpression on DNMT1 is shown in Figure 3-1, available at https://doi.org/10.1523/JNEUROSCI.0695-19.2019.f3-1.

DRG, and ipsilateral L4 spinal cord dorsal horn (data not shown). To further confirm that CREB could directly regulate Dnmt1 gene transcriptional activity, we performed luciferase assay on the transfected HEK293T cells. Cotransfection of CREB vector (encoding full-length CREB), but not control GFP vector, significantly increased the transcriptional activity of the Dnmt1 gene promoter including the CREB-binding motif (Fig. $3 d$ ). Singlecell RT-PCR analysis revealed coexpression of Creb mRNA and Dnmt1 mRNA in individual small, medium, and large DRG neurons (Fig. 3e). Together, our findings suggest that CREB participates in the nerve injury-induced upregulation of DNMT1 in the injured DRG.

\section{DRG DNMT1 contributes to neuropathic pain development}

To examine whether the increased DRG DNMT1 contributes to neuropathic pain genesis, we first observed the effect of systemic administration of RG108, a specific DNMT inhibitor, on SNLinduced pain hypersensitivity. Consistent with previous studies (Li et al., 2017; Mo et al., 2018), SNL produced long-term mechanical allodynia, heat hyperalgesia, and cold allodynia on the ipsilateral side in the vehicle-treated mice (Fig. 4a,b). Intraperitoneal injection of RG108 (daily for $7 \mathrm{~d}$ ) did not alter basal paw responses to mechanical, heat, or cold stimuli on the ipsilateral side of sham mice (Fig. $4 a, b$ ) but significantly attenuated SNLinduced mechanical allodynia, heat hyperalgesia, and cold allodynia $(p<0.05$ or $p<0.01$; Fig. $4 a, b)$. As expected, systemic injection of neither RG108 nor vehicle changed basal paw withdrawal responses on the contralateral side (Fig. 4-1a, available at https://doi.org/10.1523/JNEUROSCI.0695-19.2019.f4-1; Fig. 4-1b, available at https://doi.org/10.1523/JNEUROSCI.069519.2019.f4-1) or locomotor functions (Fig. 4-2, available at https://doi.org/10.1523/JNEUROSCI.0695-19.2019.f4-2) during the observation period.
Intraperitoneal injection of RG108 may mimic systemic administration of the drugs in clinic, but an important limitation of this strategy is the lack of anatomical specificity. To determine the role of DRG DNMT1 in neuropathic pain, we microinjected AAV5-Cre to the ipsilateral L4 DRG of Dnmt $1{ }^{\mathrm{fl} / \mathrm{fl}}$ mice and allowed 5 weeks for Cre expression before SNL or sham surgery to obtain L4 DRG-specific DNMT1 knockdown. AAV5-GFP was used as a control. As expected, SNL increased the level of DNMT1 by 1.9 -fold on day 7 after SNL in the injured L4 DRG of the AAV5-GFP-injected Dnmt $1^{\mathrm{fl} / \mathrm{fl}}$ mice compared with the AAV5GFP-injected sham Dnmt $1^{\mathrm{fl} / \mathrm{fl}}$ mice $(p<0.01$; Fig. 5a). DRG microinjection of AAV5-Cre blocked this increase as demonstrated by $44 \%$ reduction in the amount of DNMT1 in the injured L4 DRG of the AAV5-Cre-injected SNL Dnmt ${ }^{\mathrm{fl} / \mathrm{fl}}$ mice compared with the AAV5-GFP-injected SNL Dnmt $1{ }^{\mathrm{fl} / \mathrm{fl}}$ mice $(p<$ 0.01 ; Fig. 5a). This microinjection partially reversed SNLinduced increased withdrawal frequencies to mechanical stimuli $(p<0.01$; Fig. $4 c)$ and decreased withdrawal latencies to heat and cold stimuli ( $p<0.01$; Fig. $4 d$ ) on the ipsilateral side from day 3 to 7 after SNL. DRG microinjection of AAV5-Cre slightly reduced basal expression of DNMT1 protein in the ipsilateral L4 DRG of sham Dnmt $1^{\mathrm{fl} / \mathrm{fl}}$ mice $(p<0.05$; Fig. $5 a)$. DRG microinjection of neither AAV5-Cre (Fig. 4c,d; Fig. 4-1c, available at https://doi.org/10.1523/JNEUROSCI.0695-19.2019.f4-1; Fig. 4-1d, available at https://doi.org/10.1523/JNEUROSCI.0695-19.2019. f4-1) nor AAV5-GFP (data not shown) significantly altered basal mechanical, heat, and cold responses on both ipsilateral and contralateral sides of sham Dnmt $1^{\mathrm{fl} / \mathrm{fl}}$ mice. As expected, both $D n m t 1^{\mathrm{fl} / \mathrm{fl}}$ mice and virus-microinjected mice displayed normal locomotor functions (Fig. 4-2, available at https://doi.org/10.1523/ JNEUROSCI.0695-19.2019.f4-2).

DRG microinjection may cause cell damage, although the injected DRG retained its structural integrity and displayed no sig- 


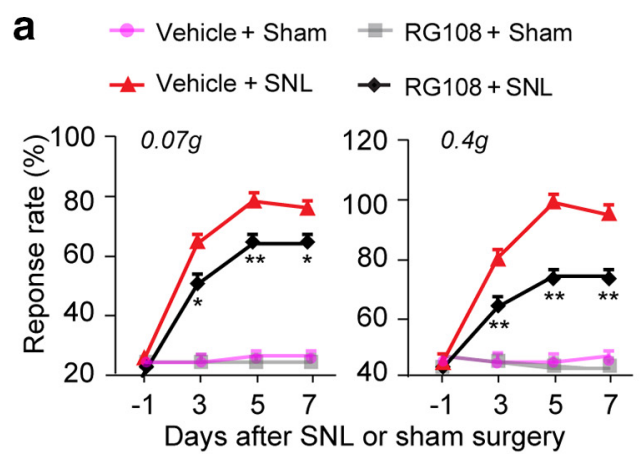

$\mathbf{C} \leftarrow \mathrm{GFP}+\mathrm{SNL} \rightleftharpoons \mathrm{Cre}+\mathrm{Sham} \rightarrow \mathrm{Cre}+\mathrm{SNL}$

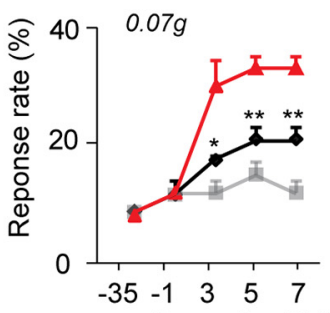

Days after SNL or sham surgery

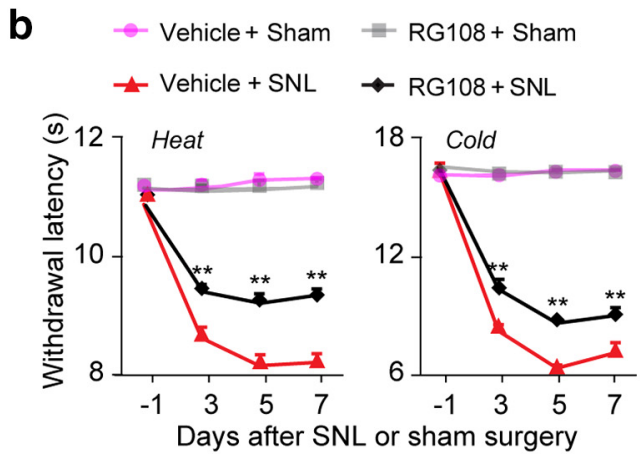

d

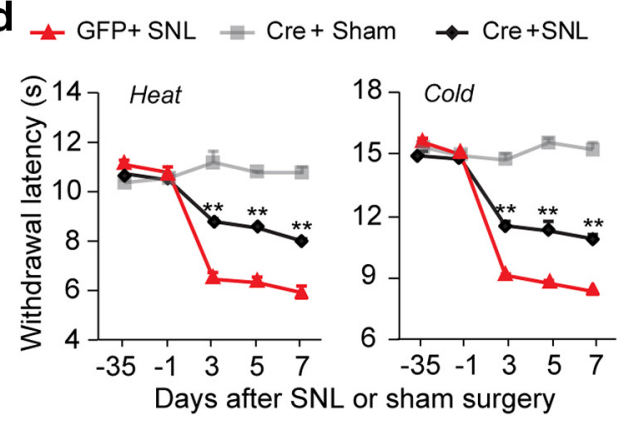

e

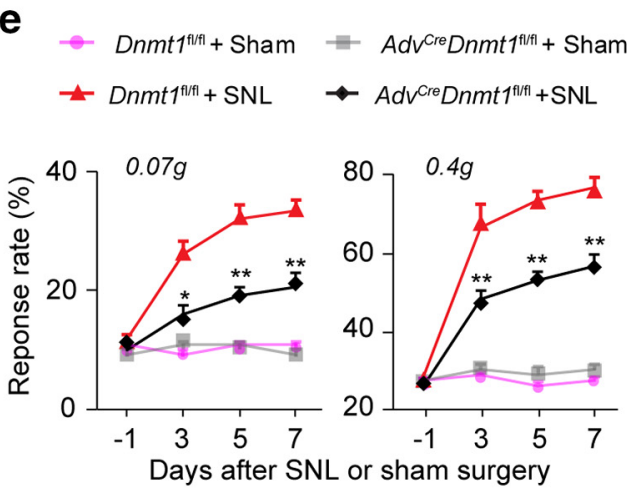

f
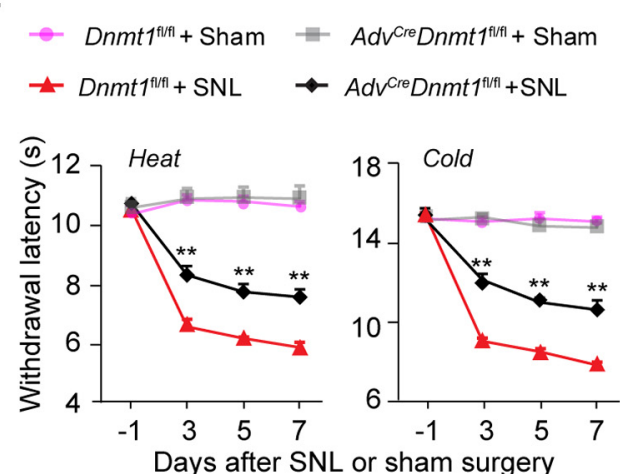

Figure 4. DRG DNMT1 contributes to SNL-induced neuropathic pain. $\boldsymbol{a}, \boldsymbol{b}$, Effect of intraperitoneal administration of RG108 $(0.4 \mathrm{mg} / \mathrm{kg})$ once daily for $7 \mathrm{~d}$ starting 30 min before surgery on SNL-induced mechanical allodynia $(\boldsymbol{a})$ and heat hyperalgesia and cold allodynia $(\boldsymbol{b})$ on the ipsilateral side. $n=5$ mice/group. Two-way ANOVA followed by post hoc Tukey test: $F_{\text {group }}(3,64)=202.3$ and $F_{\text {time }}(3,64)=74.84$ for $0.07 \mathrm{~g} ; F_{\text {group }}(3,64)=178.9$ and $F_{\text {time }}(3,64)=54.58$ for $0.4 \mathrm{~g} ; F_{\text {group }}(3,64)=611.5$ and $F_{\text {time }}(3,64)=124.6$ for heat; $F_{\text {group }}(3,64)=1823$ and $F_{\text {time }}(3,64)=637.4$ for cold. ${ }^{*} p<0.05$ versus the vehicle-treated SNL mice at the corresponding time point. ${ }^{* *} p<0.01$ versus the vehicle-treated SNL mice at the corresponding time point. $c, d$, Effect of microinjection of AAV5-Cre or AAV5-GFP into the ipsilateral L4 DRG of Dnmt $7^{\mathrm{fl} / f l}$ mice on SNL-induced mechanical allodynia $(\boldsymbol{c})$ and heat hyperalgesia and cold allodynia $(\boldsymbol{d})$ on the ipsilateral side. $n=6$ mice/group. Two-way ANOVA followed by post hoc Tukey test: $F_{\text {group }}(2,75)=39.56$ and $F_{\text {time }}(4,75)=28.35$ for $0.07 \mathrm{~g} ; F_{\text {group }}(2,75)=57.21, F_{\text {time }}(4,75)=31.22$ for $0.4 \mathrm{~g} ; F_{\text {group }}(2,75)=136.6$ and $F_{\text {time }}(4,75)=85.46$ for heat; $F_{\text {group }}(2,75)=303.8$ and $F_{\text {time }}(4,75)=173.9$ for cold. ${ }^{*} p<0.05$ versus the AAV5-GFP-microinjected SNL mice at the corresponding time point. ${ }^{* *} p<0.01$

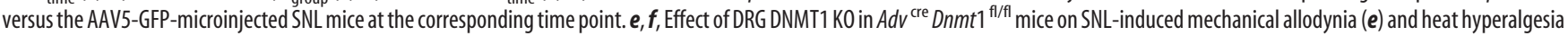
and cold allodynia $(f)$ on the ipsilateral side. $n=6$ mice/group. Two-way ANOVA followed by post hoc Tukey test: $F_{\text {group }}(3,80)=46.06, F_{\text {time }}(3,80)=12.78$ for $0.07 \mathrm{~g} ; F_{\text {group }}(3,80)=154.3, F_{\text {time }}$ $(3,80)=52.28$ for $0.4 \mathrm{~g} ; F_{\text {group }}(3,80)=227.1, F_{\text {time }}(3,80)=55.17$ for heat; $F_{\text {group }}(3,80)=374.7, F_{\text {time }}(3,80)=139.8$ for cold. ${ }^{*} p<0.05$. versus the Dnmt $f^{\mathrm{fl} / \mathrm{fl}}$ SNL mice at the corresponding time point. ${ }^{* *} p<0.01$ versus the $D n m t 7^{f / / f l} \mathrm{SNL}$ mice at the corresponding time point. Paw withdrawal frequencies in response to mechanical stimuli and paw withdrawal latencies in response to heat stimulation on the contralateral side are shown in Figure 4-1, available at https://doi.org/10.1523/JNEUROSCI.0695-19.2019.f4-1. Locomotor functions are shown in Figure 4-2, available at https://doi.org/10.1523/JNEUROSCI.0695-19.2019.f4-2.

nificant changes in the number of cells (data not shown). In addition, the limited volume of DRG microinjection may affect the efficacy of DRG DNMT1 knockdown and its downstream gene expression. To further confirm the role of DRG DNMT1 in neuropathic pain, we crossbred Advillin-Cre mice with $D n m t 1^{\mathrm{fl} / \mathrm{fl}}$ mice to generate sensory neuron-specific Dnmt1 KO $\left(A d v^{C r e} D n m t 1^{\mathrm{f} / \mathrm{fl}}\right)$ mice. DNMT1 protein was almost absent in DRGs and trigeminal ganglions, and its levels remained unchanged in the spinal cord dorsal horn and brain from $A d v^{C r e} D n m t 1^{\mathrm{fl} / \mathrm{fl}}$ mice compared with $D n m t 1^{\mathrm{fl} / \mathrm{fl}}$ mice (Fig. 5-1 $a$, available at https://doi.org/10.1523/JNEUROSCI.069519.2019.f5-1). Expression of neither DNMT3a nor DNMT3b was affected in DRGs from $A d v^{C r e} D n m t 1^{\mathrm{fl} / \mathrm{fl}}$ mice compared with
Dnmt ${ }^{\mathrm{fl} / \mathrm{fl}}$ mice (Fig. 5-1b, available at https://doi.org/10.1523/ JNEUROSCI.0695-19.2019.f5-1). Like AAV5-Cre-injected Dnmt1 $1^{\mathrm{fl} / \mathrm{fl}}$ mice, $A d v^{C r e} D n m t 1^{\mathrm{fl} / \mathrm{fl}}$ mice displayed reduced paw withdrawal frequencies to mechanical stimuli and increased paw withdrawal latencies to heat or cold stimulation compared with $D n m t 1^{\mathrm{fl} / \mathrm{fl}}$ mice on the ipsilateral side from day 3 to day 7 after SNL. Similarly, mechanical, heat, or cold stimuli-induced responses did not change on the ipsilateral side of both $D n m t 1^{\mathrm{fl} / \mathrm{fl}}$ mice and $A d v^{C r e}$ Dnmt $1{ }^{\mathrm{fl} / \mathrm{fl}}$ mice after sham surgery (Fig. $4 e, f$ ) and on the contralateral side of both mice after SNL or sham surgery (Fig. 4-1e, available at https://doi.org/10.1523/JNEUROSCI.069519.2019.f4-1; Fig. 4-1f, available at https://doi.org/10.1523/ 

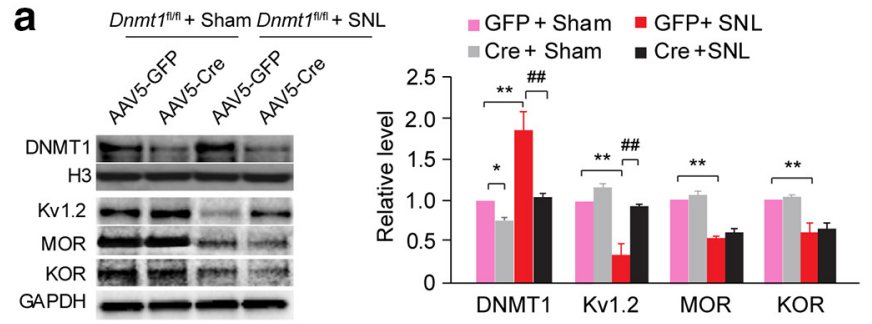

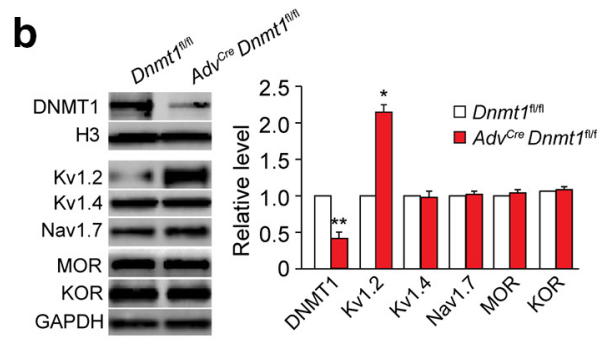

e

d

C
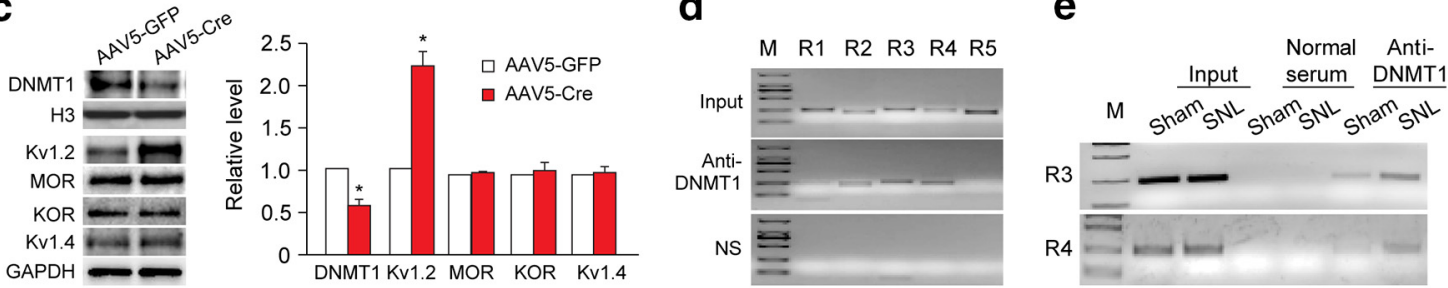
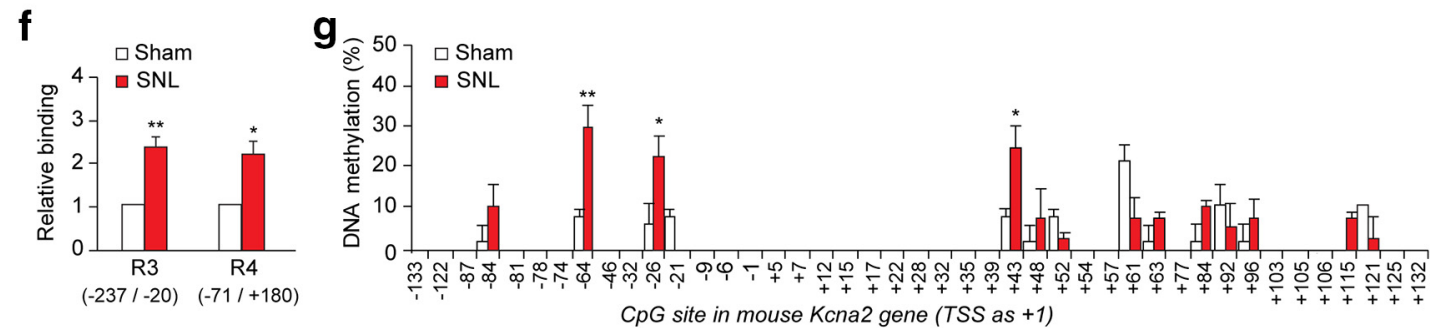

h

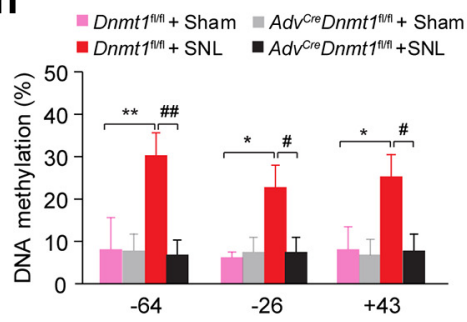

Figure 5. DNMT1 deficiency rescued SNL-induced Kv1.2 expression in the injured DRG. $\boldsymbol{a}$, Protein expression of DNMT1, Kv1.2, MOR, and KOR in the ipsilateral L4 DRG microinjected with AAV5-Cre or AAV5-GFP from Dnmt ${ }^{\mathrm{fl} / \mathrm{fl}}$ mice. $n=3$ repeats $\left(12\right.$ mice)/group. One-way ANOVA followed by post hoc Tukey test: $F_{\text {model }}(1,8)=37.1, F_{\text {injection }}(1,8)=26.1$ for Kv1.2; $F_{\text {model }}(1,8)=192.0$, $F_{\text {injection }}(1,8)=4.2$ for MOR; $F_{\text {model }}(1,8)=41.6, F_{\text {injection }}(1,8)=0.32$ for KOR. ${ }^{*} p<0.05$ versus the corresponding AAV5-GFP-microinjected sham mice. ${ }^{* *} p<0.01$ SNL versus the corresponding AAV5-GFP-microinjected sham mice. ${ }^{\# \#}<0.01$ versus the corresponding AAV5-GFP-microinjected SNL mice. $\boldsymbol{b}$, Protein expression of DNMT1, Kv1.2, Kv1.4, Nav1.7, MOR, and KOR in naive L4 DRG from Dnmt $1^{\mathrm{fl} / \mathrm{fl}}$ mice and $A d v^{\text {cre }} D n m t 1^{\mathrm{f} / \mathrm{fl}}$ mice. $n=3$ repeats (12 mice)/group. ${ }^{*} p<0.05$ versus the corresponding Dnmt $7^{\mathrm{fl} / \mathrm{fl}}$ mice (two-tailed Student's $t$ test). ${ }^{* *} p<0.01$ versus the corresponding Dnmt $1^{\mathrm{fl} / \mathrm{fl}}$ mice (two-tailed Student's $t$ test). c, Protein expression DNMT1, Kv1.2, MOR, KOR, and KV1.4 in cultured DRG neurons from Dnmt ${ }^{\mathrm{f} / \mathrm{fl}}$ mice transfected with AAV5-Cre or AAV5-GFP. ${ }^{*} p<0.01$ versus the corresponding AAV5-GFP-treated group (two-tailed Student's $t$ test). $\boldsymbol{d}$, Three regions (R2, $\left.-459 /-218 ; R 3,-237 /-20 ; R 4,-71 / 180\right)$, but not other two regions (R1, $-626 /-440 ; R 5,161 / 396)$ from the Kcna2 gene were immunoprecipitated by rabbit DNMT1 antibody, but not by rabbit normal serum (NS), in mouse DRGs. Input: total purified fragments. M, Ladder marker. $e$, $f$, DNMT1 binding to R3 and R4 regions within Kcna 2 gene in the ipsilateral L 4 DRG of mice on day 7 after SNL or sham surgery. $n=3$ repeats (10 mice)/group. ${ }^{*} p<$ 0.05 versus the corresponding sham mice (two-tailed Student's $t$ test). ${ }^{* *} p<0.01$ versus the corresponding sham mice (two-tailed Student's $t$ test). $\boldsymbol{g}$, The increases in the levels of DNA methylation at $-64,-26$, and $43 \mathrm{CpG}$ sites by bisulfite clone-sequencing assay in the ipsilateral L4 DRGs on day 7 after SNL. $n=3$ repeats (30 mice)/group. ${ }^{*} p<0.05$ versus the corresponding sham mice (two-tailed Student's $t$ test). ${ }^{* *} p<0.01$ versus the corresponding sham mice (two-tailed Student's $t$ test). $\boldsymbol{h}$, DNA methylation levels at $-64,-26$, and 43 CpG sites in the ipsilateral L4 DRG of $D n m t 1^{\mathrm{f} / / \mathrm{fl}}$ mice or $A d v^{\text {cre }} D n m t 1^{\mathrm{f} / / \mathrm{fl}}$ mice on day 7 after SNL or sham surgery. $n=3$ repeats $(30$ mice $) /$ group. One-way ANOVA followed by post hoc Tukey test: $F_{\text {model }}(1,8)=21.77, F_{\text {genotype }}(1,8)=$ 27.58 for site $-64 ; F_{\text {model }}(1,8)=20.73, F_{\text {genotype }}(1,8)=16.21$ for site $-26 ; F_{\text {model }}(1,8)=17.57, F_{\text {genotype }}(1,8)=18.84$ for site $43 .{ }^{*} p<0.05$ versus the corresponding sham Dnmt $1^{\text {fl/fl }}$ mice. ${ }^{* *} p<0.01$ versus the corresponding sham Dnmt ${ }^{\mathrm{f} / \mathrm{fl}}$ mice. ${ }^{\#} p<0.05$ versus the corresponding SNL Dnmt ${ }^{\mathrm{f} / \mathrm{fl}}$ mice. ${ }^{\# \#} p<0.01$ versus the corresponding SNL Dnmt $1^{\mathrm{fl} / \mathrm{fl}}$ mice. DNMT1 protein expression in cortex, spinal cord dorsal horn (DH), DRG and trigeminal ganglion (TG) from Dnmt $1^{\text {fl/fl }}$ mice or Adv ${ }^{\text {cre }}$ Dnmt $7^{\text {fl/fl }}$ mice is shown in Figure 5-1a, available at https://doi.org/10.1523/ JNEUROSCI.0695-19.2019.f5-1. No changes in DNMT3a and DNMT3b expression in DRGs from Dnmt $7^{\mathrm{fl} / \mathrm{fl}}$ mice or Adv ${ }^{\text {Cre }}$ Dnmt $7^{\mathrm{fl} / \mathrm{fl}}$ mice is shown in Figure 5-1b, available at https://doi.org/10.1523/ JNEUROSCI.0695-19.2019.f5-1.

JNEUROSCI.0695-19.2019.f4-1). Both Dnmt1 ${ }^{\mathrm{fl} / \mathrm{fl}}$ mice and $A d v^{\text {Cre }}$ Dnmt $1^{\mathrm{f} / \mathrm{fl}}$ mice displayed normal locomotor functions (Fig. 4-2, available at https://doi.org/10.1523/JNEUROSCI. 0695-19.2019.f4-2).

Together, our findings indicate that DNMT1 in the injured DRG may be required for neuropathic pain genesis.

\section{Upregulated DNMT1 participates in SNL-induced Kv1.2 downregulation in DRG}

Consistent with previous observations (Zhao et al., 2013, 2017; Fan et al., 2014; Liang et al., 2016a,b), SNL dramatically downregulated the expression of Kv1.2, MOR, and KOR on day 7 after SNL in the injured DRG of the AAV5-GFP-injected mice com- 
pared with the AAV5-GFP-injected sham Dnmt $1^{\mathrm{f} / \mathrm{fl}}$ mice $(p<$ 0.01; Fig. 5a). Blocking the increased DRG DNMT1 through microinjection of AAV5-Cre into the ipsilateral L4 DRG of $D n m t 1^{\mathrm{fl} / \mathrm{fl}}$ mice reversed the SNL-induced downregulation of Kv1.2, but not MOR and KOR, in the injured DRG on day 7 after SNL $(p<0.01 ;$ Fig. $5 a)$. Although DRG microinjection of AAV5Cre did not significantly increase basal expression of Kv1.2 in the injured L4 DRG of sham Dnmt $1^{\mathrm{fl} / \mathrm{fl}}$ mice (Fig. 5a), $A d v^{C r e} D n m t 1^{\mathrm{fl} / \mathrm{fl}}$ mice exhibited a marked increase in the level of Kv1.2 and no changes in the amounts of MOR, KOR, Kv1.4, and Nav1.7 in the DRG compared with Dnmt $1^{\mathrm{fl} / \mathrm{fl}}$ mice (Fig. $5 b$ ). Consistently, in cultured DRG neurons from the Dnmt1 $1^{\mathrm{fl} / \mathrm{fl}}$ mice, knockdown of DNMT1 through addition of AAV5-Cre significantly increased the level of Kv1.2 without affecting the expression of MOR, KOR, and Kv1.4 compared with the AAV5-GFP-treated cells (Fig. $5 c$ ). These findings indicate that DNMT1 epigenetically silences Kcna2 gene expression in the injured DRG after SNL.

As shown in Figure 3e, Dnmt1 mRNA coexpressed with Kcna2 mRNA in the individual small, medium, and large DRG neurons, suggesting direct DNMT1 regulation of Kcna2 in the DRG neurons. We performed ChIP assay and revealed that DNMT1 preferentially binds to three regions (R2: $-459 /-218$ bp; R3: $-237 /$ -20 bp; R4: $-71 / 180$ bp) of Kcna2 gene, as demonstrated by the amplification of only these three regions (of 5 regions from -626 to $396 \mathrm{bp}$ ) from the complexes immunoprecipitated with DNMT1 antibody in nuclear fractions from naive mouse DRG (Fig. $5 d$ ). Basal binding density in the $\mathrm{R} 2$ is weaker than those in the R3 and R4 (Fig. 5d). Furthermore, the binding activities in the R3 and R4 from the injured DRG on day 7 after SNL increased by 2.2 -fold $(p<0.01)$ and 2.1 -fold $(p<0.05)$, respectively, compared with those after sham surgery (Fig. $5 e, f)$. These increased binding activities might alter the DNA methylation pattern and level within the R3 and R4 of the Dnmt1 gene after SNL. Indeed, we used the bisulfite clone-sequencing assay and showed significant increases in the level of DNA methylation at $-64,-26$, and $43 \mathrm{CpG}$ sites from -133 to $132 \mathrm{bp}$ of Kcna2 gene containing high density of $\mathrm{CpG}$ islands (Fig. 5g). These sites are located within DNMT1 binding regions (i.e., R3 and R4) described above. The increased DNA methylation at these three sites was DNMT1dependent, as $A d v^{C r e} D n m t 1^{\mathrm{f} / \mathrm{fl}}$ mice failed to display SNLinduced increases in the methylation levels at $-64,-26$, and 43 CpG sites (Fig. 5h).

\section{Upregulated DNMT1 participates in SNL-induced neuronal hyperexcitability in DRG}

Given that DRG Kv1.2 is a key player in neuronal excitability (Zhao et al., 2013, 2017; Liang et al., 2016b), we finally examined whether blocking the SNL-induced increase of DRG DNMT1 affected Kv1.2-gated neuronal hyperexcitability in the injured DRG. Whole-cell voltage-clamp recording was performed in acute disassociated neurons from the ipsilateral L4 DRG of $D n m t 1^{f l / f l}$ mice or $A d v^{C r e} D n m t 1^{\mathrm{fl} / \mathrm{fl}}$ mice $7-10 \mathrm{~d}$ after SNL or sham surgery. Compared with sham surgery, total Kv current densities were markedly reduced in large, medium, and small DRG neurons from SNL Dnmt $1^{\mathrm{f} / \mathrm{fl}}$ mice $(p<0.01$; Fig. $6 a, b$, $d, e, g, h)$. These reductions were almost fully reversed in DRG neurons from SNL $A d v^{\text {cre }} D n m t 1^{\mathrm{f} / \mathrm{fl}}$ mice $(p<0.01$; Fig. $6 a, b$, $d, e, g, h)$. No significant differences were observed in total Kv current from large, medium, and small neurons of the ipsilateral L4 DRG between sham $A d v^{\text {cre }} D n m t 1^{\mathrm{fl} / \mathrm{fl}}$ mice and sham Dnmt $1^{\mathrm{fl} / f \mathrm{l}}$ mice (Fig. $6 a, b, d, e, g, h$ ). Bath application of $100 \mathrm{~nm}$ maurotoxin (MTX), a selective Kcna2 current inhibitor, produced less reduc- tions in $\mathrm{Kv}$ current from large and medium DRG neurons from SNL Dnmt $1{ }^{\mathrm{fl} / \mathrm{fl}}$ mice than that from sham $D n m t 1^{\mathrm{f} / / \mathrm{fl}}$ mice or sham $A d v^{C r e} D n m t 1^{\mathrm{fl} / \mathrm{fl}}$ mice $(p<0.05$; Fig. $6 c, f)$, indicating that Kv1.2 channel expression in large and medium neurons was reduced in the injured SNL DRG. Nevertheless, the large and medium DRG neurons from SNL $A d v^{\mathrm{cre}} D n m t 1^{\mathrm{f} / \mathrm{fl}}$ mice exhibited marked reduction in Kv current similar to those from sham $D n m t 1^{\mathrm{f} / \mathrm{fl}}$ mice upon MTX treatment ( $p<0.05$; Fig. $6 c, f)$, suggesting that blocking SNL-induced DNMT1 increase rescues Kv1.2 downregulation in the injured DRG. In small DRG neurons from either $D n m t 1^{\mathrm{f} / / \mathrm{l}}$ mice or $A d v^{\text {cre }} D n m t 1^{\mathrm{fl} / \mathrm{fl}}$ mice, MTX did not lead to significant current reductions or marked differences between SNL or sham surgery (Fig. 6i), which is consistent with the evidence that a majority of small DRG neurons lack Kv1.2 expression (Rasband et al., 2001; Fan et al., 2014).

Whole-cell current-clamp recording was also performed to examine neuronal excitability from the ipsilateral L4 DRG of $D n m t 1^{f l / f l}$ mice or $A d v^{C r e} D n m t 1^{\mathrm{fl} / \mathrm{fl}}$ mice $7-10 \mathrm{~d}$ after SNL or sham surgery. Compared with sham Dnmt $1^{\mathrm{t} / \mathrm{l} / \mathrm{l}}$ mice, large, medium, and small DRG neurons from SNL Dnmt $1^{\mathrm{f} / \mathrm{fl}}$ mice showed increases by $8.2,8.2$, and $11.6 \mathrm{mV}$, respectively, in the resting membrane potentials ( $p<0.01$; Fig. $7 a$ ) and decreases by $22.8 \%$, $55.3 \%$, and $47.4 \%$, respectively, in the current thresholds for AP generation $(p<0.05$; Fig. $7 b)$. As expected, large, medium, and small DRG neurons from SNL Dnmt ${ }^{\mathrm{f} / \mathrm{fl}}$ mice also displayed increases in the number of APs compared with those in sham $D n m t 1^{\mathrm{fl} / \mathrm{fl}}$ mice $(p<0.05$ or $p<0.01$; Fig. $7 c-f)$. However, neither SNL nor sham surgery produced significant changes in the resting membrane potentials, the current thresholds, and the number of APs in the large, medium, and small DRG neurons from $A d v^{\text {cre }} D n m t 1^{\mathrm{fl} / \mathrm{fl}}$ mice $(p<0.05$ or $p<0.01$; Fig. $7 a-f)$. No significant changes in membrane input resistance and other AP parameters, such as threshold, amplitude, overshoot, or afterhyperpolarization amplitude, were observed in any of the treated groups (Fig. 7-1, available at https://doi.org/10.1523/ JNEUROSCI.0695-19.2019.f7-1). Together, these data indicated that blocking SNL-induced increase in DRG DNMT1 could prevent neuronal hyperexcitability in the injured DRG.

\section{Discussion}

Neuropathic pain has been fully studied for several decades, but how pain hypersensitivities are caused under this disorder is still not completely understood. In the present study, we reported that peripheral nerve injury upregulated DNMT1 expression through activation of the transcription factor CREB in the sensory neurons of the injured DRGs. This upregulation correlates with an elevation in the level of DNA methylation at some CpG sites within the Kcna2 promoter and $5^{\prime}$ - untranslated regions and is associated with nerve injury-induced Kcna2 downregulation and neuronal hyperexcitability in the injured DRG. Blocking the upregulated DRG DNMT1 alleviated the development of nerve injury-induced pain hypersensitivities. Given that DRG Kv1.2 is a key player in neuropathic pain genesis, DRG DNMT1 likely contributes to the mechanisms that underlie neuropathic pain development.

DNMT1 is expressed widely throughout the central and peripheral nervous system (Kadriu et al., 2012; Pollema-Mays et al., 2014; Noguchi et al., 2015). A previous study showed that immunostaining of DNMT1 was detected ubiquitously in the nuclei of rat DRG neurons and Schwann cells and not detectable in the satellite cells (Pollema-Mays et al., 2014). However, this conclusion remains to be further confirmed because no specific neuronal and glial markers were used (Pollema-Mays et al., 2014). The 
a Large

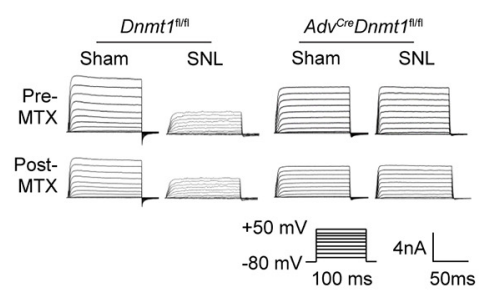

d Medium

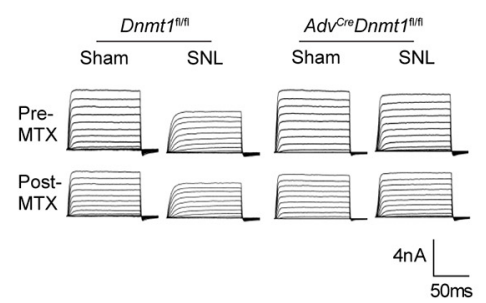

g small

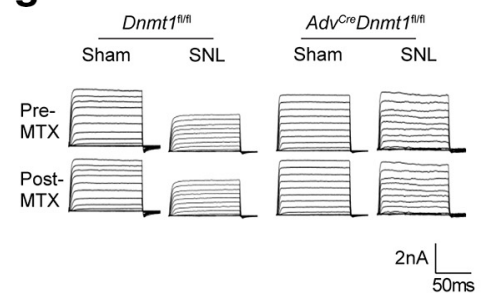

b

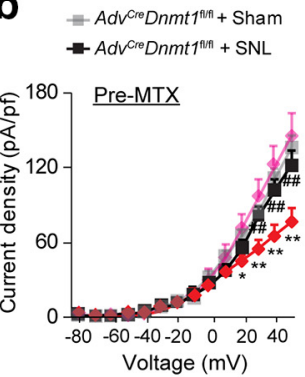

e

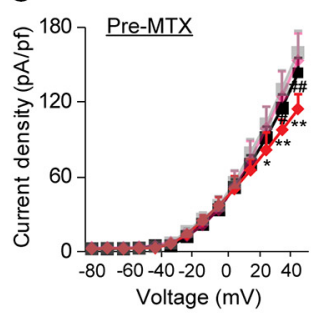

h

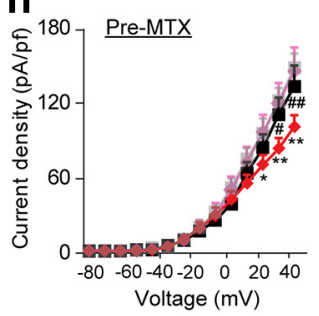

$\rightarrow$ Dnmt $1^{n+1}+$ Sham

$\rightarrow D n m t^{1+11+}+$ SNL

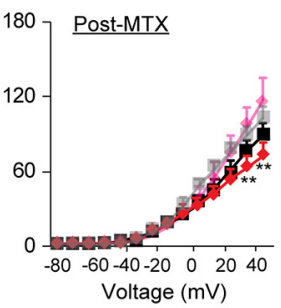

Voltage $(\mathrm{mV})$
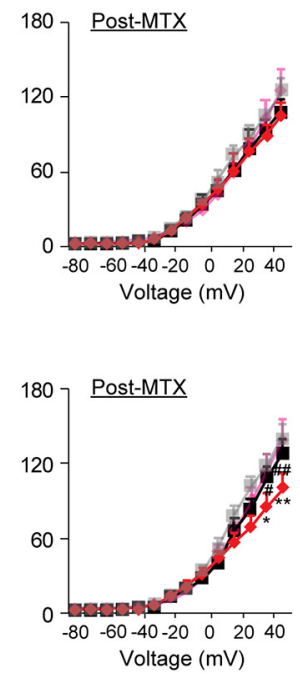

C

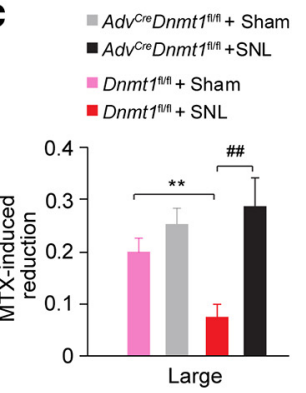

f

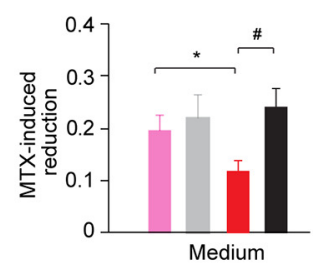

i

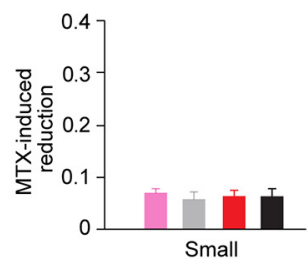

Figure 6. DRG DNMT1 KO rescued SNL-induced decrease of total Kv current in the injured DRG neurons from Dnmt $7^{\mathrm{fl} / \mathrm{fl}}$ mice or Adv ${ }^{\text {cre }}$ Dnmt $7^{\mathrm{fl} / \mathrm{fl}}$ mice on day 7 after SNL or sham surgery. $\boldsymbol{a}, \boldsymbol{b}$, Representative traces of total Kv currents $(\boldsymbol{a})$ and $/-V$ curve $(\boldsymbol{b})$ before or after bath perfusion of $100 \mathrm{~nm} \mathrm{MTX} \mathrm{in} \mathrm{large} \mathrm{DRG} \mathrm{neurons.} n=5-7$ mice/group $(n=16$ neurons from sham Dnmt 7 fl/fi mice, $n=18$ neurons from SNL Dnmt $1^{\mathrm{fl} / \mathrm{fl}}$ mice, $n=19$ neurons from sham $A d v^{\mathrm{cre}} D n m t 7^{\mathrm{fl} / \mathrm{fl}}$ mice, $n=19$ neurons from SNL Adv ${ }^{\text {cre }} D n m t 1^{\text {ffl/fl }}$ mice). Two-way ANOVA followed by post hoc Tukey test: $F_{\text {group }}(3,952)=17.2 .{ }^{*} p<0.05$ versus the sham Dnmt ${ }^{f / / f l}$ mice at the corresponding voltage. ${ }^{* *} p<0.01$ versus the sham Dnmt $1^{\mathrm{f} / \mathrm{fl}}$ mice at the corresponding voltage. ${ }^{\# \#} p<0.01$ versus SNL $D n m t f^{\mathrm{t} / \mathrm{fl}}$ mice at the corresponding voltage. $c$, MTX-induced reductions in total Kv currents at $40 \mathrm{mV}$ in large neurons from four groups as indicated above. $n=5-7$ mice/group. One-way ANOVA followed by post hoc Tukey test: $F_{\text {model }}(1,68)=1.44, F_{\text {genotype }}(1,68)=12.1$. ${ }^{* *} p<0.01$ versus sham Dnmt $1^{\mathrm{fl} / \mathrm{fl}}$ mice. ${ }^{\# \#} p<0.01$ versus SNL Dnmt $1^{\mathrm{fl} / \mathrm{fl}}$ mice. $\boldsymbol{d}, \boldsymbol{e}$, Representative traces of total Kv currents $(\boldsymbol{d})$ and $I-V$ curve $(\boldsymbol{e})$ before or after bath perfusion of $100 \mathrm{~nm} \mathrm{MTX} \mathrm{in} \mathrm{medium} \mathrm{DRG} \mathrm{neurons.} n=5-7$ mice/group ( $n=19$ neurons from sham Dnmt $7^{\text {fl/fl }}$ mice, $n=25$ neurons from SNL

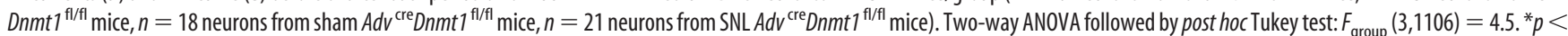
0.05 versus the sham Dnmt $7^{\mathrm{fl} / \mathrm{fl}}$ mice at the corresponding voltage. ${ }^{* *} p<0.01$ versus the sham Dnmt $1^{\mathrm{fl} / \mathrm{fl}}$ mice at the corresponding voltage. ${ }^{\#} p<0.05$ versus SNL Dnmt $1^{\mathrm{f} / \mathrm{fl}}$ mice at the corresponding voltage. ${ }^{\# \#} p<0.01$ versus SNL Dnmt $7^{\mathrm{fl} / \mathrm{fl}}$ mice at the corresponding voltage. $f$, MTX-induced reductions in total Kv currents at $40 \mathrm{mV}$ in medium neurons from four groups as indicated above. $n=5-7$ mice/group. One-way ANOVA followed by post hoc Tukey test: $F_{\text {model }}(1,79)=0.788, F_{\text {genotype }}(1,79)=4.94 .{ }^{*} p<0.05$ versus sham Dnmt $1^{\mathrm{fl} / \mathrm{fl}}$ mice. ${ }^{\#} p<0.05$ versus SNL Dnmt $f^{f / f / f}$ mice. $\boldsymbol{g}, \boldsymbol{h}$, Representative traces of total Kv currents $(\boldsymbol{g})$ and $l-V$ curve $(\boldsymbol{h})$ before or after bath perfusion of $100 \mathrm{~nm} \mathrm{MTX}$ in small DRG neurons. $n=5-7$ mice/group ( $n=17$ neurons from sham Dnmt ${ }^{\mathrm{f} / \mathrm{fl}}$ mice, $n=19$ neurons from SNL Dnmt $7^{\mathrm{fl} / \mathrm{fl}}$ mice, $n=19$ neurons from sham Adv ${ }^{\text {cre }} \mathrm{Dnmt} t^{\mathrm{fl} / \mathrm{fl}}$ mice, $n=22$ neurons from SNLAdv ${ }^{\text {cre }}$ Dnmt $7^{\mathrm{fl} / \mathrm{fl}}$ mice). Two-way ANOVA followed by post hoc Tukey test: $F_{\text {group }}(3,1022)=8.4$. ${ }^{*} p<0.05$ versus the sham Dnmt $7^{\mathrm{fl} / \mathrm{fl}}$ mice at the corresponding voltage. ${ }^{* *} p<0.01$ versus the sham Dnmt $7^{\mathrm{fl} / \mathrm{f}}$ mice at the corresponding voltage. ${ }^{\#} p<$ 0.05 versus SNL Dnmt $1^{\mathrm{flf} / \mathrm{f}}$ mice at the corresponding voltage. ${ }^{\# \#} p<0.01$ versus SNL Dnmt $7^{\mathrm{fl} / \mathrm{fl}}$ mice at the corresponding voltage. $i$, MTX-induced reductions in total Kv currents at $40 \mathrm{mV}$ in small neurons from four groups as indicated above. $n=5-7$ mice/group. One-way ANOVA by post hoc Tukey test: $F_{\text {model }}(1,73)=2.37, F_{\text {genotype }}(1,73)=6.14$.

present study demonstrated that DNMT1 was coexpressed exclusively with NeuN in the nuclei of mouse DRG sensory neurons and was undetected in the GS-labeled satellite cells. A majority of DNMT1-labeled neurons are medium in size. Our observations further identified a neuronal location for DNMT1 in the DRG and suggest the participation of DRG DNMT1 in neuropathic pain.

Peripheral nerve injury can transcriptionally activate the Dnmt1 gene in the DRG. SNL, CCI, or sciatic nerve axotomy increased the expression of Dnmt1 mRNA and its protein in the injured DRG, but not in intact DRG and ipsilateral spinal cord. It seems likely that Dnmt1 gene activation is tissue-specific in response to peripheral nerve injury. Our quantitative Western blot analysis showed that the level of DNMT1 was increased on days 3 and 7 after SNL and returned to basal level on day 14 after SNL. Given that SNL-induced pain hypersensitivities occurred on day 3 after SNL and reach a peak on day 5-7 after SNL (Zhao et al.,
2013, 2017; Liang et al., 2016b; Li et al., 2017) and that pharmacological preinhibition or genetic knockdown/KO of DRG DNMT1 attenuated SNL-induced pain hypersensitivity on days 3-7 after SNL, we concluded that DNMT1 contributed to neuropathic pain genesis. Although we did not have the evidence to identify the role of DNMT1 in neuropathic pain maintenance, our findings suggest that DNMT1 is a potential target at the early stage of neuropathic pain.

Nerve injury-induced Dnmt1 gene expression was regulated by the transcription factor CREB in the injured DRG. Although other potential binding motifs for three transcription factors (MZF1, OCT1, and CEBP $\beta$ ) were also identified within the promoter and $5^{\prime}$-untranslated region of the Dnmt1 gene, these three transcription factors did not affect DNMT1 protein expression in the injured DRG. Whether additional transcription factors are involved in Dnmt1 gene activation following nerve injury remains to be investigated. In addition, we cannot rule out other 

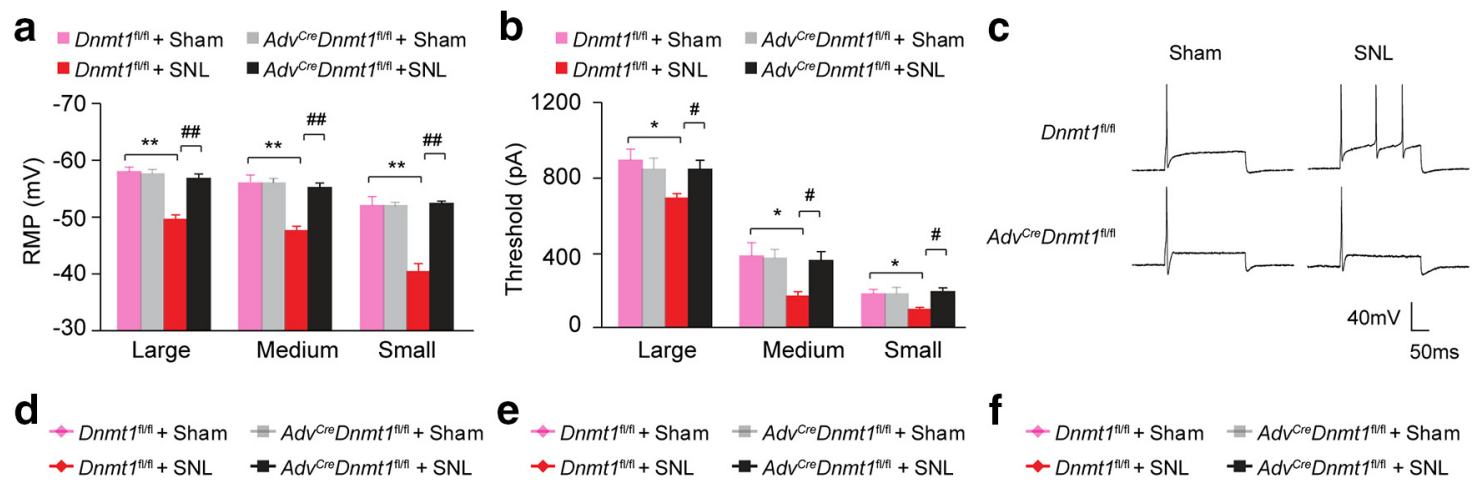

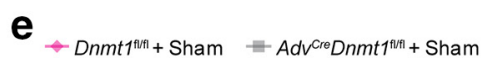
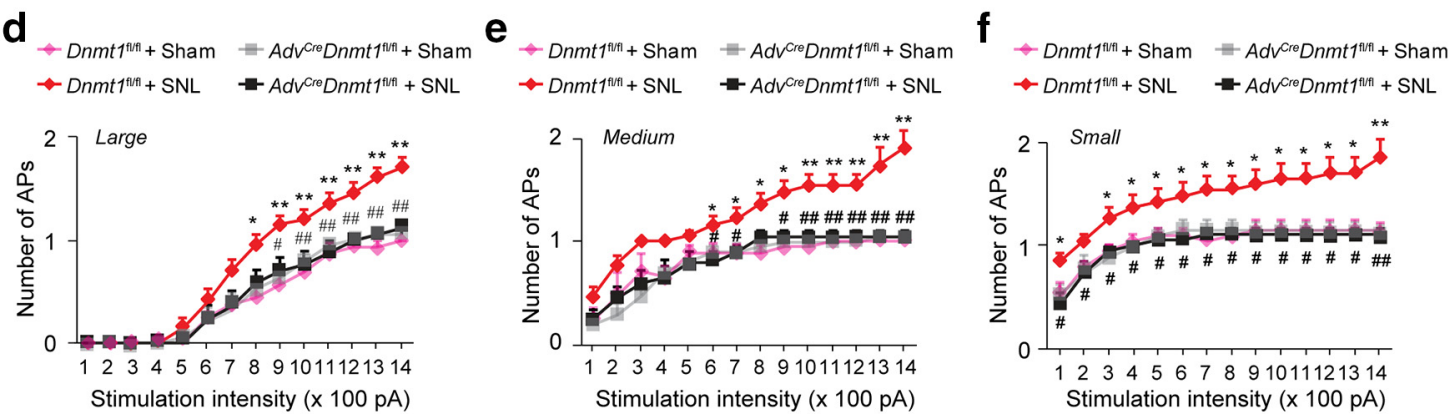

Figure 7. DRG DNMT1 KO resumed SNL-induced hyperexcitability in injured DRG neurons from Dnmt ${ }^{f / / f 1}$ mice or $A d v^{\text {cre } D n m t ~}{ }^{f / f 1}$ mice on day 7 after SNL or sham surgery. $\boldsymbol{a}$, Resting membrane potentials from large, medium, and small DRG neurons. $n=5-7$ mice/group ( $n=16$ large, 17 medium, and 20 small neurons from sham Dnmt $1^{\text {fl/fl }}$ mice; $n=20$ large, 19 medium, and $19 \mathrm{small}$ neurons from SNL Dnmt $1^{\mathrm{fl} / \mathrm{fl}}$ mice; $n=19$ large, 21 medium, and 19 small neurons from sham Adv ${ }^{\mathrm{cre}} \mathrm{Dnmt} 1^{\mathrm{ff} / \mathrm{fl}}$ mice; and $n=17$ large, 20 medium, and 19 small neurons from SNL Adv ${ }^{\mathrm{cre}} \mathrm{Dnmt} \mathrm{f}^{\mathrm{fl} / \mathrm{fl}}$ mice). One-way ANOVA followed by post hoc Tukey test: $F_{\text {model }}(1,68)=22.3, F_{\text {genotype }}(1,68)=13.7$ for large; $F_{\text {model }}(1,73)=20.6, F_{\text {genotype }}(1,73)=14.7$ for medium; $F_{\text {model }}(1,73)=29.0$, $F_{\text {genotype }}(1,73)=30.9$ for small. ${ }^{* *} p<0.01$ versus sham Dnmt $f^{\mathrm{fl} / \mathrm{fl}}$ mice. ${ }^{\# \#} p<0.01$ versus SNL Dnmt ${ }^{f / f / 1}$ mice. $\boldsymbol{b}$, Current thresholds from large, medium, and small DRG neurons. Numbers of the recorded cells and mice used are the same as in $\boldsymbol{a}$. One-way ANOVA followed by posthoc Tukey test: $F_{\text {model }}(1,68)=4.96, F_{\text {genotype }}(1,68)=1.52$ for large; $F_{\text {model }}(1,73)=5.47, F_{\text {genotype }}(1,73)=$ 2.77 for medium; $F_{\text {model }}(1,73)=3.62, F_{\text {genotype }}(1,73)=5.54$ for small. ${ }^{*} p<0.05$ versus sham Dnmt $1^{\mathrm{fl} / \mathrm{fl}}$ mice. ${ }^{\#} p<0.05$ versus SNLDnmt $7^{\mathrm{fl} / \mathrm{fl}}$ mice. $c_{\text {, }}$ Representative traces of evoked APs in DRG neurons. $\boldsymbol{d}-\boldsymbol{f}$, Numbers of evoked APs after application of different currents as indicated. Number of neurons recorded are the same as in $\boldsymbol{a}$. Numbers of the recorded cells and mice used are the same as in $\boldsymbol{a}$. Two-way ANOVA followed by post hoc Tukey test: $F_{\text {model }}(3,952)=51.4$ for large, $F_{\text {model }}(3,1106)=68.1$ for medium, $F_{\text {model }}(3,1022)=67.4$ for small. ${ }^{*} p<0.05$ versus sham Dnmt $7^{\mathrm{fl} / \mathrm{fl}}$ mice at the corresponding stimulation intensity. ${ }^{* *} p<0.01$ versus sham Dnmt $1^{\mathrm{fl} / \mathrm{fl}}$ mice at the corresponding stimulation intensity. ${ }^{\#} p<0.05$ versus SNL Dnmt $7^{\mathrm{fl} / \mathrm{fl}}$ mice at the corresponding stimulation intensity. ${ }^{\# \#} p<0.01$ versus SNL Dnmt $1^{\mathrm{f} / \mathrm{fl}}$ mice at the corresponding stimulation intensity. Membrane input resistance and other action potential parameters in DRG neurons are shown in Figure 7-1, available at https://doi.org/10.1523/JNEUROSCI.0695-19.2019.f7-1.

potential possibilities (e.g., epigenetic modifications and/or increased mRNA stability) that may participate in the nerve injuryinduced increase of DNMT1 in the injured DRG.

The upregulated DNMT1 contributes to nerve injuryinduced Kcna2 downregulation in the injured DRG. Dnmt1 mRNA, Creb mRNA, and Kcna2 mRNA coexpress in individual DRG neurons of naive mice. Blocking the SNL-induced increase in DRG DNMT1 through microinjection of AAV5-Cre into the ipsilateral L4 DRG of SNL Dnmt $1^{f l / f l}$ mice rescued the expression of Kv1.2, but not MOR and KOR, in the injured DRG. Interestingly, microinjection of AAV5-Cre into the ipsilateral L4 DRG of sham Dnmt $1^{f l / f l}$ mice did not affect basal DRG Kv1.2 expression, although this microinjection moderately reduced basal expression of DRG DNMT1. In contrast, naive $A d v^{\mathrm{cre}} \mathrm{Dnmt1} 1^{\mathrm{fl} / \mathrm{fl}}$ mice displayed a marked reduction in basal amount of DNMT1 and a significant increase in basal level of Kv1.2 without altering basal expression of MOR, KOR, Kv1.4, and Nav1.7 in DRG. No effect of DRG AAV5-Cre microinjection on basal Kv1.2 expression in the injected DRG of sham Dnmt $1^{f l f l}$ mice may be related to lower efficacy of the injected AAV5-Cre due to the limited volume of DRG microinjection. This conclusion is supported by our in vitro experiment, which revealed that addition of enough AAV5-Cre markedly decreased basal expression of DNMT1 and increased basal expression of Kv1.2 in the cultured DRG neurons from $D n m t 1^{f l f l}$ mice. Although how DNMT1 specifically targets Kcna2 is unclear, the contribution of DNMT1 to nerve injury-induced DRG Kcna2 gene silencing may be associated with an increase in binding of DNMT1 to the Kcna2 promoter and 5' -untranslated regions $(-459 / 180)$ as well as an elevation in DNA methylation levels within these regions after peripheral nerve injury. Indeed, there were the increases in the levels of DNA methylation at -64, -26 , and $43 \mathrm{CpG}$ sites within the Kcna2 gene in the injured DRG on day 7 after SNL. These increases are DNMT1-dependent as blocking the SNL-induced increase in DRG DNMT1 abolished the SNL-induced elevation in Kcan2 DNA methylation level within these three CpG sites. Our findings, consistent with previous reports (Hong et al., 2015), demonstrate that DNMT1 may be inducible and mediate de novo methylation of the Kcna2 gene under neuropathic pain conditions. Although the SNL-induced increases in DRG DNA methylation were identified within the higher density of CpG islands ( $-133 / 132$ bp) of the Kcna2 gene, whether the SNL-induced DNA methylation increases at additional CpG sites of the Kcna2 gene and/or at other genes remains to be identified.

Multiple mechanisms participate in nerve injury-induced DRG Kcna2 downregulation. In addition to DNMT1, DNMT3atriggered DRG de novo DNA methylation and G9a-triggered histone methylation contribute to nerve injury-induced Kcna2 silencing in the injured DRG (Liang et al., 2016b; Zhao et al., 2017). Nerve injury-induced upregulation of endogenous long noncoding Kcna2 antisense RNA was also responsible for Kcna2 downregulation in the injured DRG (Zhao et al., 2013). We recently reported that methyl-CpG-binding domain protein 1 (MDB1) repressed Kcna2 gene expression through recruitment of DNMT3a into the Kcna2 gene promoter (Mo et al., 2018), but detailed mechanisms of how these epigenetic repressors work together to regulate Kcna2 gene expression and whether they interact 
and/or affect each other under neuropathic pain conditions are still unclear and remain to be addressed in future studies.

It is generally believed that nerve injury-induced increase in spontaneous ectopic firing and hyperexcitability in DRG neurons play a critical role in neuropathic pain development (Tal et al., 1999; Liu et al., 2000). Kv1.2 reduction in DRG neurons decreased the total voltage-gated potassium current, depolarized the resting membrane potential, decreased the current threshold for activation of APs, increased the number of APs in DRG neurons, and produced neuropathic pain-like symptoms (Zhao et al., 2013; Fan et al., 2014). Blocking nerve injury-induced reduction of Kv1.2 expression in the injured DRG alleviated neuropathic pain during the development period (Zhao et al., 2013; Fan et al., 2014). These findings suggest that DRG Kv1.2 is a key player in neuropathic pain genesis. The present study showed that blocking the SNL-induced increase in DRG DNMT1 rescued total Kv current, attenuated the SNL-induced increases in the resting membrane potential and number of AP, and reversed the SNLinduced decrease in current threshold for AP in the injured medium and large DRG neurons. Interestingly, these phenomena were also seen in the injured small DRG neurons, although Kv1.2-mediated current was not altered due to poor Kv1.2 expression in small DRG neurons (Zhao et al., 2013; Fan et al., 2014). Kv1.4 is expressed highly in small DRG neurons (Rasband et al., 2001), but its expression could not be regulated by DNMT1 in the DRG. Given that blocking the SNL-induced increase in DRG DNMT1 rescued total Kv current and attenuated the SNLinduced increase of neuronal excitability in small DRG neurons, DNMT1 likely participates in the nerve injury-induced downregulation of other Kv channels expressed in small DRG neurons. Moreover, the involvement of DNMT1 in nerve injury-induced silencing of non-Kv channel genes cannot be excluded at present. Previous studies revealed that substance P and CGRP in the injured myelinated fibers and in large and medium DRG are significantly increased as early as $2 \mathrm{~d}$ after nerve injury (Weissner et al., 2006). Our behavioral observations indicate that blocking the SNL-induced increase in DRG DNMT1 significantly reduced mechanical, heat, and cold hypersensitivities during the development period. Thus, nerve injury-induced upregulation of DRG DNMT1 contributes to neuropathic pain genesis likely by repressing at least Kcna2 gene expression in the injured DRG.

In conclusion, our study showed the DNMT1-triggered epigenetic silencing of Kcna2 gene in the injured DRG under neuropathic pain conditions. Given that blocking the upregulated DRG DNMT1 alleviated neuropathic pain genesis without affecting acute pain and locomotor function, DNMT1 may be a potential target for neuropathic pain management.

\section{References}

Asgatay S, Champion C, Marloie G, Drujon T, Senamaud-Beaufort C, Ceccaldi A, Erdmann A, Rajavelu A, Schambel P, Jeltsch A, Lequin O, Karoyan P, Arimondo PB, Guianvarc'h D (2014) Synthesis and evaluation of analogues of N-phthaloyl-L-tryptophan (RG108) as inhibitors of DNA methyltransferase 1. J Med Chem 57:421-434.

Campbell JN, Meyer RA (2006) Mechanisms of neuropathic pain. Neuron 52:77-92.

Coluzzi F, Pappagallo M (2005) Opioid therapy for chronic noncancer pain: practice guidelines for initiation and maintenance of therapy. Minerva Anestesiol 71:425-433.

Dong E, Locci V, Gatta E, Grayson DR, Guidotti A (2019) N-phthalyl-1tryptophan (RG108), like clozapine (CLO), induces chromatin remodeling in brains of prenatally stressed mice. Mol Pharmacol 95:62-69.

Du H, Le Y, Sun F, Li K, Xu Y (2019) ILF2 directly binds and stabilizes CREB to stimulate malignant phenotypes of liver cancer cells. Anal Cell Pathol (Amst) 2019:1575031.
Fan L, Guan X, Wang W, Zhao JY, Zhang H, Tiwari V, Hoffman PN, Li M, Tao YX (2014) Impaired neuropathic pain and preserved acute pain in rats overexpressing voltage-gated potassium channel subunit Kv1.2 in primary afferent neurons. Mol Pain 10:8.

Fatemi M, Hermann A, Pradhan S, Jeltsch A (2001) The activity of the murine DNA methyltransferase Dnmt1 is controlled by interaction of the catalytic domain with the N-terminal part of the enzyme leading to an allosteric activation of the enzyme after binding to methylated DNA. J Mol Biol 309:1189-1199.

Hong S, Zheng G, Wiley JW (2015) Epigenetic regulation of genes that modulate chronic stress-induced visceral pain in the peripheral nervous system. Gastroenterology 148:148-157.e7.

Jeltsch A (2006) Molecular enzymology of mammalian DNA methyltransferases. Curr Top Microbiol Immunol 301:203-225.

Jongen JL, Huijsman ML, Jessurun J, Ogenio K, Schipper D, Verkouteren DR, Moorman PW, van der Rijt CC, Vissers KC (2013) The evidence for pharmacologic treatment of neuropathic cancer pain: beneficial and adverse effects. J Pain Symptom Manage 46:581-590.e1.

Kadriu B, Guidotti A, Chen Y, Grayson DR (2012) DNA methyltransferases1 (DNMT1) and 3a (DNMT3a) colocalize with GAD67-positive neurons in the GAD67-GFP mouse brain. J Comp Neurol 520:19511964.

Latremoliere A, Woolf CJ (2009) Central sensitization: a generator of pain hypersensitivity by central neural plasticity. J Pain 10:895-926.

Lee CY, Perez FM, Wang W, Guan X, Zhao X, Fisher JL, Guan Y, Sweitzer SM, Raja SN, Tao YX (2011) Dynamic temporal and spatial regulation of mu opioid receptor expression in primary afferent neurons following spinal nerve injury. Eur J Pain 15:669-675.

Liang L, Lutz BM, Bekker A, Tao YX (2015) Epigenetic regulation of chronic pain. Epigenomics 7:235-245.

Liang L, Zhao JY, Gu X, Wu S, Mo K, Xiong M, Marie Lutz B, Bekker A, Tao YX (2016a) G9a inhibits CREB-triggered expression of mu opioid receptor in primary sensory neurons following peripheral nerve injury. Mol Pain 12:1744806916682242.

Liang L, Gu X, Zhao JY, Wu S, Miao X, Xiao J, Mo K, Zhang J, Lutz BM, Bekker A, Tao YX (2016b) G9a participates in nerve injury-induced Kcna2 downregulation in primary sensory neurons. Sci Rep 6:37704.

Li Z, Gu X, Sun L, Wu S, Liang L, Cao J, Lutz BM, Bekker A, Zhang W, Tao YX (2015) Dorsal root ganglion myeloid zinc finger protein 1 contributes to neuropathic pain after peripheral nerve trauma. Pain 156:711-721.

Li Z, Mao Y, Liang L, Wu S, Yuan J, Mo K, Cai W, Mao Q, Cao J, Bekker A, Zhang W, Tao YX (2017) The transcription factor C/EBP beta in the dorsal root ganglion contributes to peripheral nerve trauma-induced nociceptive hypersensitivity. Sci Signal 10:eaam5345.

Liu CN, Wall PD, Ben-Dor E, Michaelis M, Amir R, Devor M (2000) Tactile allodynia in the absence of $\mathrm{C}$-fiber activation: altered firing properties of DRG neurons following spinal nerve injury. Pain 85:503-521.

Lorincz MC, Schübeler D, Hutchinson SR, Dickerson DR, Groudine M (2002) DNA methylation density influences the stability of an epigenetic imprint and Dnmt3a/b-independent de novo methylation. Mol Cell Biol 22:7572-7580.

Lutz BM, Bekker A, Tao YX (2014) Noncoding RNAs: new players in chronic pain. Anesthesiology 121:409-417.

Mao Q, Wu S, Gu X, Du S, Mo K, Sun L, Cao J, Bekker A, Chen L, Tao YX (2019) DNMT3a-triggered downregulation of K2p 1.1 gene in primary sensory neurons contributes to paclitaxel-induced neuropathic pain. Int J Cancer. Advance online publication. Retrieved January 26, 2019. doi:10.1002/ijc.32155.

Meyer R, Patel AM, Rattana SK, Quock TP, Mody SH (2014) Prescription opioid abuse: a literature review of the clinical and economic burden in the united states. Popul Health Manag 17:372-387.

Miao XR, Fan LC, Wu S, Mao Q, Li Z, Lutz B, Xu JT, Lu Z, Tao YX (2017) DNMT3a contributes to the development and maintenance of bone cancer pain by silencing Kv1.2 expression in spinal cord dorsal horn. Mol Pain 13:1744806917740681.

Mo K, Wu S, Gu X, Xiong M, Cai W, Atianjoh FE, Jobe EE, Zhao X, Tu WF, Tao YX (2018) MBD1 contributes to the genesis of acute pain and neuropathic pain by epigenetic silencing of Oprm1 and Kcna2 genes in primary sensory neurons. J Neurosci 38:9883-9899.

Noguchi H, Kimura A, Murao N, Matsuda T, Namihira M, Nakashima K (2015) Expression of DNMT1 in neural stem/precursor cells is critical for 
survival of newly generated neurons in the adult hippocampus. Neurosci Res 95:1-11.

Okano M, Bell DW, Haber DA, Li E (1999) DNA methyltransferases Dnmt3a and Dnmt3b are essential for de novo methylation and mammalian development. Cell 99:247-257.

Poetsch AR, Plass C (2011) Transcriptional regulation by DNA methylation. Cancer Treat Rev 37 [Suppl 1]:S8-S12.

Pollema-Mays SL, Centeno MV, Apkarian AV, Martina M (2014) Expression of DNA methyltransferases in adult dorsal root ganglia is cell-type specific and up regulated in a rodent model of neuropathic pain. Front Cell Neurosci 8:217.

Pradhan S, Bacolla A, Wells RD, Roberts RJ (1999) Recombinant human DNA (cytosine-5) methyltransferase: I. Expression, purification, and comparison of de novo and maintenance methylation. J Biol Chem 274:33002-33010.

Rasband MN, Park EW, Vanderah TW, Lai J, Porreca F, Trimmer JS (2001) Distinct potassium channels on pain-sensing neurons. Proc Natl Acad Sci U S A 98:13373-13378.

Shao C, Gao Y, Jin D, Xu X, Tan S, Yu H, Zhao Q, Zhao L, Wang W, Wang D (2017) DNMT3a methylation in neuropathic pain. J Pain Res 10: 2253-2262.

Siedlecki P, Zielenkiewicz P (2006) Mammalian DNA methyltransferases. Acta Biochim Pol 53:245-256.

Sun L, Zhao JY, Gu X, Liang L, Wu S, Mo K, Feng J, Guo W, Zhang J, Bekker A, Zhao X, Nestler EJ, Tao YX (2017) Nerve injury-induced epigenetic silencing of opioid receptors controlled by DNMT3a in primary afferent neurons. Pain 158:1153-1165.

Tal M, Wall PD, Devor M (1999) Myelinated afferent fiber types that become spontaneously active and mechanosensitive following nerve transection in the rat. Brain Res 824:218-223.
Tollefsbol TO, Hutchison CA 3rd (1997) Control of methylation spreading in synthetic DNA sequences by the murine DNA methyltransferase. J Mol Biol 269:494-504.

Vilkaitis G, Suetake I, Klimasauskas S, Tajima S (2005) Processive methylation of hemimethylated CpG sites by mouse Dnmt1 DNA methyltransferase. J Biol Chem 280:64-72.

Weissner W, Winterson BJ, Stuart-Tilley A, Devor M, Bove GM (2006) Time course of substance $\mathrm{P}$ expression in dorsal root ganglia following complete spinal nerve transection. J Comp Neurol 497:78-87.

Wu S, Marie Lutz B, Miao X, Liang L, Mo K, Chang YJ, Du P, Soteropoulos P, Tian B, Kaufman AG, Bekker A, Hu Y, Tao YX (2016) Dorsal root ganglion transcriptome analysis following peripheral nerve injury in mice. Mol Pain 12:1744806916629048.

Xu B, Cao J, Zhang J, Jia S, Wu S, Mo K, Wei G, Liang L, Miao X, Bekker A, Tao YX (2017) Role of MicroRNA-143 in nerve injury-induced upregulation of Dnmt3a expression in primary sensory neurons. Front Mol Neurosci 10:350.

Yuan J, Wen J, Wu S, Mao Y, Mo K, Li Z, Su S, Gu H, Ai Y, Bekker A, Zhang W, Tao YX (2019) Contribution of dorsal root ganglion octamer transcription factor 1 to neuropathic pain after peripheral nerve injury. Pain 160:375-384

Zhao JY, Liang L, Gu X, Li Z, Wu S, Sun L, Atianjoh FE, Feng J, Mo K, Jia S, Lutz BM, Bekker A, Nestler EJ, Tao YX (2017) DNA methyltransferase DNMT3a contributes to neuropathic pain by repressing Kcna2 in primary afferent neurons. Nat Commun 8:14712.

Zhao X, Tang Z, Zhang H, Atianjoh FE, Zhao JY, Liang L, Wang W, Guan X, Kao SC, Tiwari V, Gao YJ, Hoffman PN, Cui H, Li M, Dong X, Tao YX (2013) A long noncoding RNA contributes to neuropathic pain by silencing Kcna2 in primary afferent neurons. Nat Neurosci 16:1024-1031. 